\title{
Genomic Imprinting in Mammals
}

\author{
Denise P. Barlow ${ }^{1}$ and Marisa S. Bartolomei ${ }^{2}$ \\ ${ }^{1}$ CeMM Research Center for Molecular Medicine of the Austrian Academy of Sciences, CeMM, 1090 Vienna, Austria; \\ ${ }^{2}$ Department of Cell and Developmental Biology, University of Pennsylvania Perelman School of Medicine, \\ Philadelphia, Pennsylvania 19104-6148 \\ Correspondence: dbarlow@cemm.oeaw.ac.at and bartolom@mail.med.upenn.edu
}

\section{SUMMARY}

Genomic imprinting affects a subset of genes in mammals and results in a monoallelic, parental-specific expression pattern. Most of these genes are located in clusters that are regulated through the use of insulators or long noncoding RNAs (IncRNAs). To distinguish the parental alleles, imprinted genes are epigenetically marked in gametes at imprinting control elements through the use of DNA methylation at the very least. Imprinted gene expression is subsequently conferred through IncRNAs, histone modifications, insulators, and higher-order chromatin structure. Such imprints are maintained after fertilization through these mechanisms despite extensive reprogramming of the mammalian genome. Genomic imprinting is an excellent model for understanding mammalian epigenetic regulation.

\section{Outline}

1 Historical overview

2 Genomic imprinting-An epigenetic gene regulatory system

3 Key discoveries in genomic imprinting
4 Genomic imprinting-A model for mammalian epigenetic regulation

5 Future directions

References

Editors: C. David Allis, Marie-Laure Caparros, Thomas Jenuwein, and Danny Reinberg

Additional Perspectives on Epigenetics available at www.cshperspectives.org

Copyright (C 2014 Cold Spring Harbor Laboratory Press; all rights reserved; doi: 10.1101/cshperspect.a018382

Cite this article as Cold Spring Harb Perspect Biol 2014;6:a018382 


\section{OVERVIEW}

Mammals are diploid organisms whose cells possess two matched sets of chromosomes, one inherited from the mother and one from the father. Thus, mammals have two copies of every gene. Normally both the maternal and paternal copy of each gene has the same potential to be active in any cell. Genomic imprinting is an epigenetic mechanism that changes this potential because it restricts the expression of a gene to one of the two parental chromosomes. It is a phenomenon displayed by only a few hundred of the approximately 25,000 genes in our genome, the majority being expressed equally when inherited from either parent. Genomic imprinting affects both male and female offspring and is therefore a consequence of parental inheritance, not of sex. As an example of what is meant by this, an imprinted gene that is active on a maternally inherited chromosome will be active on the maternal chromosome and silent on the paternal chromosome in all males and females.

The definition of genomic imprinting is restricted here to "parental-specific gene expression in diploid cells." Thus, diploid cells that contain two parental copies of all genes will express only one parental copy of an imprinted gene and silence the other parental copy. In contrast, nonimprinted genes will be expressed from both parental gene copies in a diploid cell. To understand the concept of genomic imprinting it is important to distinguish between imprinted genes and those showing apparent parental-specific expression because of unequal parental genetic contribution to the embryo. Examples of unequal parental genetic contribution include $Y$ chromosome-linked genes present only in males, genes that escape $X$ inactivation in females (producing a double dose of X-linked gene products compared with males), mitochon- drial genes contributed mainly by the maternal parent, and messenger RNAs (mRNAs) and proteins present only in the sperm or egg cytoplasm.

Many features of genomic imprinting in mammals make it a fascinating biological problem in postgenomic times. It is intriguing that the subset of genes subject to genomic imprinting largely code for factors regulating embryonic and neonatal growth. Thus, it is likely that genomic imprinting evolved to play a specific role in mammalian reproduction. It is also providing clues as to a possible evolutionary response to parental conflict, to the adaptation of the maternal parent to an internal reproduction system, and, perhaps, providing a glimpse of the way the mammalian genome protects itself against invading DNA sequences. Genomic imprinting is an intellectually challenging phenomenon, not least because it raises the question of why a diploid organism would evolve a silencing system that forsakes the advantages of the diploid state.

At this stage of our knowledge, genomic imprinting does not appear to be widespread among the four eukaryotic kingdoms that include Protista, Fungi, Plants, and Animals. However, it does exist, in a possibly related form, in two invertebrate arthropods-Coccidae and Sciaridae, and in the endosperm of some seed-bearing plants, such as maize and Arabidopsis. This distribution indicates that genomic imprinting arose independently at least three times during the evolution of life. Surprisingly, despite this predicted independent evolution of genomic imprinting, some similarities among the imprinting mechanism are emerging. It is likely that this reflects conservation of basic epigenetic regulatory mechanisms that underlie both genomic imprinting and normal gene regulation. 


\section{HISTORICAL OVERVIEW}

The presence of genomic imprinting in mammals has considerable medical, societal, and intellectual implications in terms of (1) the clinical management of genetic traits and diseases, (2) the capacity to control human and animal breeding by assisted reproductive technologies, and (3) the progress of biotechnology and postgenomic medical research. Any modern day discussion of genetic problems, whether in research or medicine, must consider if a gene shows a biparental (i.e., diploid) mode of expression, or, is subject to genomic imprinting and shows parental-specific (i.e., haploid) expression. Despite the importance of genomic imprinting to human health and well-being, it is surprising that widespread acceptance of its existence and significance did not happen until the early nineties after three genes were unequivocally shown to display parentalspecific expression in mice.

Parental-specific behavior of whole chromosomes had been observed in cytogenetic studies of chromosomes in Arthropods as early as the 1930s (Chandra and Nanjundiah 1990). Interestingly, the term "chromosome imprinting" was first coined to describe paternal-specific chromosome elimination that plays a role in sex determination in some Arthropod species (Crouse et al. 1971). Chromosomal imprinting of the mammalian X chromosome was also noted, which leads to paternal-specific inactivation of one of the two X chromosomes in all cells of female marsupials and the extraembryonic tissues of the mouse (Cooper et al. 1971). During the same period, classical geneticists were generating mouse mutants carrying chromosomal translocations that laid the foundation for the observation of imprinted gene expression. Some of these "translocation" mice, initially used to map the position of genes on chromosomes, showed a parental-specific phenotype when certain chromosomal regions were inherited as duplications of one parental chromosome in the absence of the other parental chromosome (known as uniparental disomy or UPD; Fig. 1). These results indicated the possibility "that haploid expression of particular maternal or paternal genes is important for normal mouse development" (Searle and Beechey 1978). At the same time, other geneticists used an unusual mouse mutant known as the "hairpin-tail" mouse that carried a large deletion of chromosome 17 to unequivocally set aside a basic tenet of genetics "that organisms heterozygous at a given locus are phenotypically identical irrespective of which gamete contributes which allele to the genotype" (Johnson 1974). Instead, offspring who received the Hairpin-tail deletion from a maternal parent were increased in size and died midway through embryonic development, whereas paternal transmission of the genetically identical chromosome produced viable and fertile mice (Fig. 1). It is notable with hindsight that in spite of the

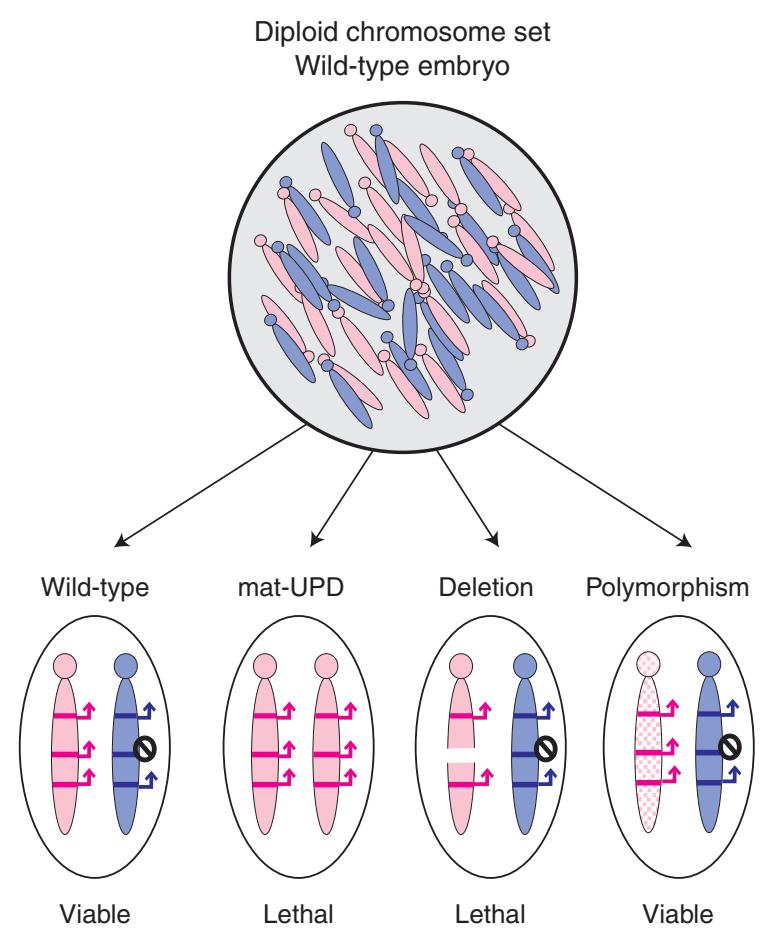

Figure 1. Mouse models to study genomic imprinting that allow the maternal and paternal chromosome to be distinguished. Mammals are diploid and inherit a complete chromosome set from the maternal and paternal parent. However, mice can be generated that (1) inherit two copies of a chromosome pair from one parent and no copy from the other parent (known as UPD), (2) inherit a partial chromosomal deletion from one parent and a wild-type chromosome from the other parent, and (3) inherit chromosomes carrying single-nucleotide polymorphisms (known as SNPs) from one parent and a wild-type chromosome from the other parent. Offspring with UPDs or deletions are likely to display lethal phenotypes, whereas SNPs will allow the production of viable offspring.

previously published description of imprinted X-chromosome inactivation in mammals, the favored interpretation of these genetic translocation and deletion experiments was not that the regions contained imprinted genes, but that genes on these autosomes primarily acted in the haploid egg or sperm to modify proteins used later in embryonic development. Despite this, the concept of differential functioning of the maternal and paternal genome was gaining ground and a suggestion made that "the maternal genome might be normally active at the Hairpin-tail chromosomal region while its paternal counterpart is preferentially inactivated" (McLaren 1979).

A major step forward in establishing the existence of genomic imprinting in mammals came several years later with the development of an improved nuclear transfer technology being used to test the possibility of generating diploid uniparental embryos solely from mouse egg nuclei. The nuclear transfer technique took a donor male or female pronucleus from a newly fertilized egg and used a fine 
micropipette to place it inside a host fertilized egg from which either the maternal or paternal pronucleus had been removed. This regenerated diploid embryos, but with two maternal or two paternal genomes (known, respectively, as gynogenetic and androgenetic embryos; Fig. 2 ). The technique was first used to show that nuclei from fertilized Hairpin-tail mutant embryos could not be rescued when transferred into a wild-type host egg. This provided proof that the embryonic genome, and not the oocyte cytoplasm, carried the Hairpin-tail defect. It also confirmed the suggestion that genes on the maternal and paternal copy of chromosome 17 functioned differently during embryonic development (McGrath and Solter 1984b). Subsequently, nuclear transfer was used to show that embryos, reconstructed from two maternal pronuclei (known as gynogenetic embryos) or two paternal pronuclei (androgenetic embryos), failed to survive; whereas only embryos reconstructed from one maternal and one paternal pronucleus produced viable and fertile offspring (McGrath and Solter 1984a; Surani et al. 1984). This work overturned a previous

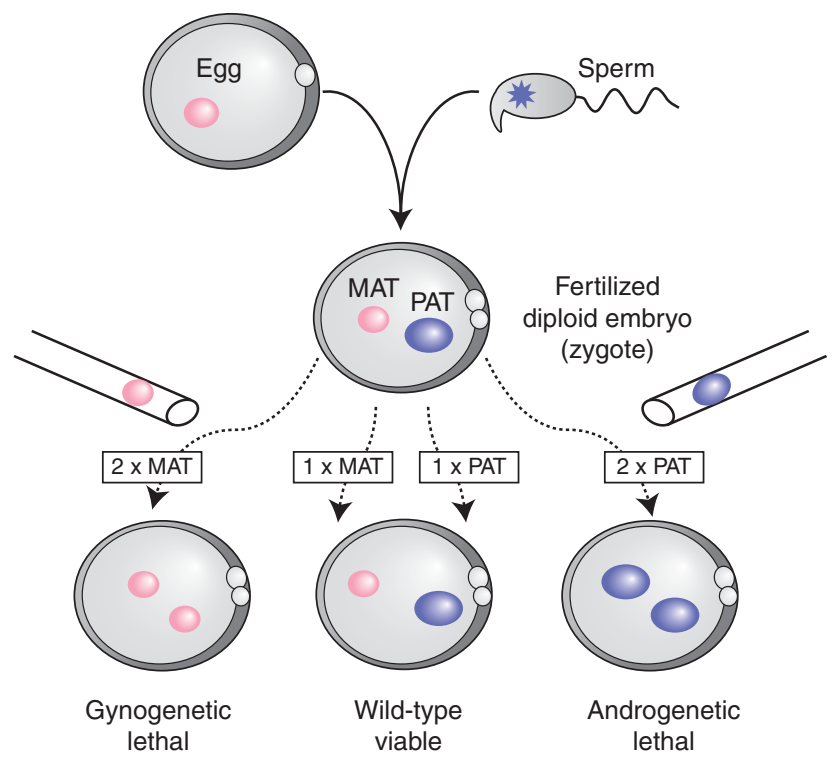

Figure 2. A maternal and paternal genome are needed for mammalian reproduction. The nuclear transfer technique used micropipettes and high-powered microscopes to remove the male or female nuclei from a newly fertilized egg and place them in various combinations into a second "host" fertilized egg that had already been enucleated, thereby generating anew diploid embryos with two maternal (gynogenetic) or two paternal (androgenetic) genomes or a biparental genome (wild-type). Gynogenetic and androgenetic embryos were lethal at early embryonic stages. Only reconstituted embryos that received both a maternal and paternal nucleus (wildtype) survived to produce living young. These experiments show the necessity for both the maternal and paternal genome in mammalian reproduction, and indicate the two parental genomes express different sets of genes needed for complete embryonic development. claim that uniparental mice could develop to adulthood (Hoppe and Illmensee 1982). Gynogenetic embryos at the time of death were defective in extraembryonic tissues that contribute to the placenta, whereas androgenetic embryos were defective in embryonic tissue. These outcomes led to the hypothesis that embryonic development required imprinted genes expressed from the maternal genome, whereas the paternal genome expressed imprinted genes required for extraembryonic development (Barton et al. 1984). Subsequent identification of imprinted genes in the mouse did not confirm a bias in the function of imprinted genes, but indicated that the observed differences between gynogenetic and androgenetic embryos may be explained by a dominant effect of one or a few imprinted genes.

The nuclear transfer experiments, combined with supporting data from mouse genetics, provided convincing evidence that both parental genomes were required for embryogenesis in mice, laying a strong foundation for the existence of genomic imprinting in mammals (Fig. 2). An extensive survey of parental chromosome contribution to embryonic development, using "translocation" mice to create UPD chromosomes (Fig. 1), identified two regions on mouse chromosomes 2 and 11 that showed opposite phenotypes when present either as two maternal or two paternal copies. This further strengthened the argument for parental-specific gene expression in mammals (Cattanach and Kirk 1985). In addition, human data strongly indicated that some genetic conditions, most notably the PraderWilli syndrome, which appears to arise exclusively by paternal transmission, could best be explained by parental-specific gene expression (Reik 1989). Further clues came from experiments applying the newly developed technology for making transgenic mice by microinjecting gene sequences into a fertilized mouse egg. This was often beset by the problem of DNA methylation unexpectedly inducing silencing of the transgene in somatic tissues. Some transgenes even showed parental-specific differences in their ability to acquire DNA methylation, adding weight to the argument that parental chromosomes behave differently. This normally followed the pattern that maternally transmitted transgenes were methylated whereas paternally transmitted transgenes were not. However, only in a few cases did DNA methylation differences correlate with parental-specific expression. Although many similarities were later found between "transgene" methylation imprinting and genomic imprinting of endogenous mouse genes, several features distinguish them (Reik et al. 1990). This includes a high susceptibility to strain-specific background effects, an inability to maintain imprinted expression at different chromosomal integration sites, and a requirement for foreign DNA sequences to produce the imprinted effect (Chaillet et al. 1995). 
Despite the wealth of supportive data, final proof of the existence of genomic imprinting in mammals depended on the identification of genes showing imprinted parentalspecific expression. This occurred in 1991 when three imprinted mouse genes were described. The first of these, $\operatorname{Igf} 2 r$ (insulin-like growth factor type 2 receptor that is a "scavenger" receptor for the growth hormone insulin-like growth factor type $2[\operatorname{Igf2}]$ ) was identified as a maternally expressed imprinted gene. This gene was later shown to explain the overgrowth phenotype of the Hairpin-tail mutant mouse (Barlow et al. 1991). A few months later, the Igf2 gene was identified as a paternally expressed imprinted gene (DeChiara et al. 1991; Ferguson-Smith et al. 1991). Finally, the H19 gene (cDNA clone number 19 isolated from a fetal hepatic library), an unusual long noncoding RNA (lncRNA) was subsequently shown to be a maternally expressed imprinted gene (Bartolomei et al. 1991). Diverse strategies were used to identify these three imprinted genes, each of which depended on emerging technologies in mouse genetics. For Igf2r, positional cloning was used to identify genes that mapped to the Hairpin-tail deletion on chromosome 17. Mice then inheriting the deletion from one parent were used to identify those genes showing maternal-specific expression (Fig. 1). For Igf2, the physiological role of this growth factor in embryonic development was being tested by gene knockout technology. Surprisingly, mice carrying the mutant nonfunctional allele showed a phenotype following paternal transmission, but no phenotype on maternal transmission. The H19 lncRNA was identified as an imprinted gene after this gene was mapped close to the Igf2 locus on chromosome 7 , proving the hypothesis that imprinted genes could be clustered together. Although these strategies were to prove useful in subsequent attempts to identify imprinted genes, the demonstration that imprinted genes were closely clustered has proven to be a pivotal discovery in understanding the mechanism controlling genomic imprinting in mammals.

\section{GENOMIC IMPRINTING -AN EPIGENETIC GENE REGULATORY SYSTEM}

The defining characteristic of genomic imprinting is that it is cis acting (see Box 1). Thus, the imprinting mechanism acts only on one chromosome. The two parental chromosomes will normally contain many single base pair differences (known as single-nucleotide polymorphisms [SNPs]) if the population is outbred, but they can be genetically identical if inbred mouse strains are used. Because genomic imprinting occurs in inbred mice that have genetically identical parental chromosomes, it was concluded that the process must use an epigenetic mechanism to modify the information carried by the DNA sequence, yet create an expression difference between the two parental gene copies. These observations also indicate that a cis-acting silencing mechanism, which is restricted to one chromosome, is operating so that the silencing factors cannot freely diffuse through the nucleus to reach the active gene copy. Although imprinted genes are repressed on one parental chromosome relative to the other, genomic imprinting is not necessarily a silencing mechanism and has the potential to operate at any level of gene regulation (i.e., at the promoter, enhancers, splicing junctions, or polyadenylation sites) to induce parental-specific differences in expression.

Genomic imprinting must therefore depend on an epigenetic system that modifies or "imprints" one of the two parental chromosomes (Fig. 3). This imprint is subsequently used to attract or repel transcriptional factors or mRNA processing factors, thereby changing expression of the imprinted gene on one parental chromosome. Because inbred mice with genetically identical chromosomes also show genomic imprinting, parental imprints are not likely to be acquired after the embryo becomes diploid because there would be no way for the cells' epigenetic machinery to distinguish between identical parental gene copies. Thus, parental imprints must be acquired when the two parental chromosome sets are separate and this only occurs during

BOX 1. KEY FEATURES OF GENOMIC IMPRINTING IN MAMMALS

- cis-acting mechanism

- A consequence of inheritance not sex

- Imprints are epigenetic modifications acquired by one parental gamete

- Imprinted genes are mostly clustered together with a noncoding RNA

- Imprints can modify long-range regulatory elements that act on multiple genes

- Imprinted genes play a role in mammalian development 


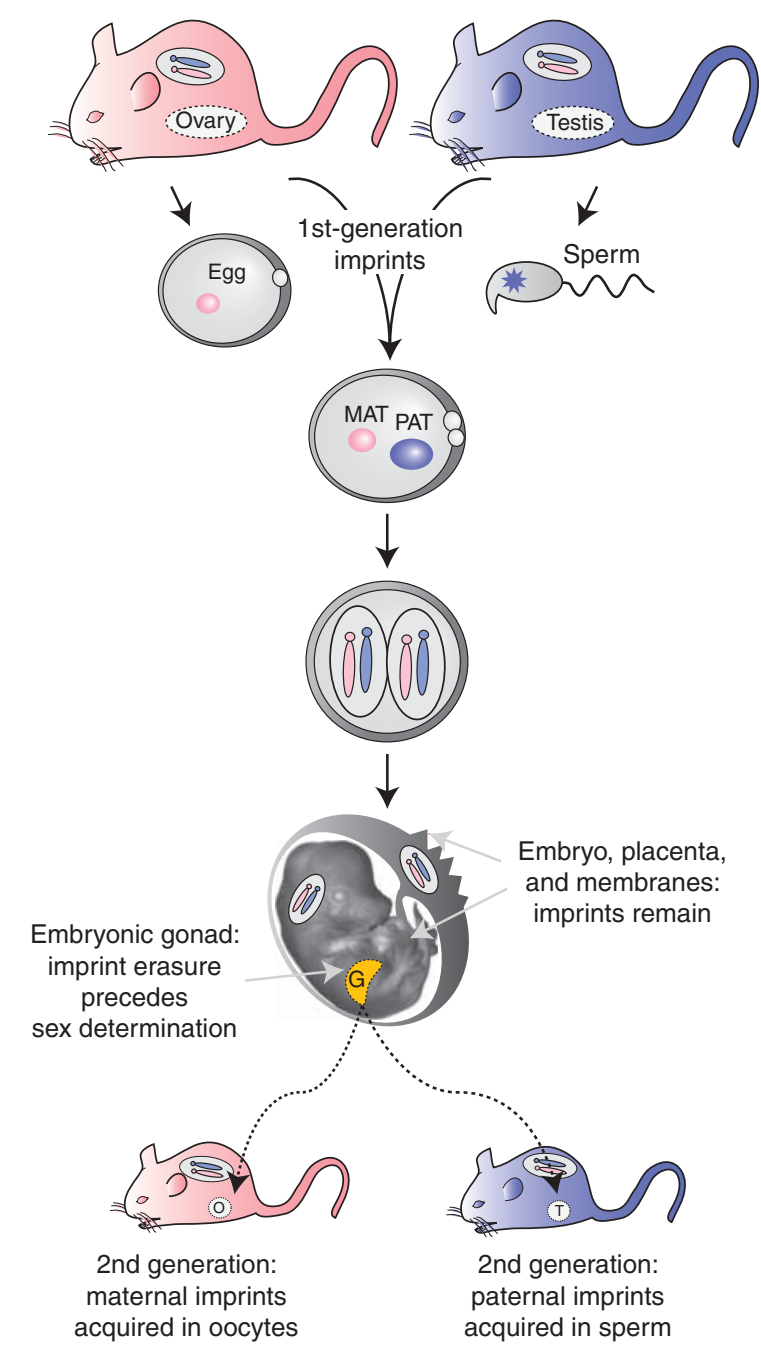

Figure 3. Imprint acquisition and erasure in mammalian development. Imprints are acquired by the gametes; thus, oocytes and sperm already carry imprinted chromosomes (first-generation imprints). After fertilization when the embryo is diploid, the imprint is maintained on the same parental chromosome after each cell division in cells of the embryo, yolk sac, placenta, and also in the adult. The germ cells are formed in the embryonic gonad and the imprints are erased only in these cells before sex determination. As the embryo develops into a male, the gonads differentiate to testes that produce haploid sperm that acquire a paternal imprint on their chromosomes. Similarly, in developing females, chromosomes in the ovaries acquire maternal imprints (second-generation imprints).

gamete formation, and for $\sim 12 \mathrm{~h}$ postfertilization (Fig. 3). The most likely scenario is that gametic imprints are placed on paternally imprinted genes during sperm production and on maternally imprinted genes during egg formation. A key feature of the "imprinted" DNA sequence is that it would only be modified in one of the two parental gametes; thus, two types of recognition system are required, one sperm-specific and one oocyte-specific, each directed toward a different DNA sequence. Several other features are required of the imprint. First, once established, it must remain on the same parental chromosome after fertilization when the embryo is diploid. Second, the imprint must be stably inherited through mitosis of the embryo and adult animal. Last, it must be erasable. The latter is necessary because the embryo will follow either a male or female developmental path midway through development and its gonads will need to produce only one type of imprinted haploid parental gamete. Thus, germ cells that have arisen from embryonic diploid cells (Fig. 3) must first lose their inherited maternal and paternal imprints before they gain that of the gamete.

How are gametic imprints identified? An imprint can be defined as the epigenetic modification that distinguishes the two parental copies of a given gene. Once formed, the imprint must also allow the transcription machinery to treat the maternal and paternal gene copy differently within the same nucleus. A gametic imprint is predicted to be continuously present at all developmental stages (Fig. 3), thus imprints can be found by comparing epigenetic modifications on maternal and paternal chromosomes in embryonic or adult tissues (using strategies outlined in Fig. 1) and tracing them back in development to one of the two gametes. Candidates for gametic imprints could be modifications of DNA or histone proteins that package DNA into chromosomes (Allis et al. 2014). There are now two types of epigenetic DNA modification known in mammals; 5methylcytosine and 5-hydroxymethylcytosine ( $\mathrm{Li}$ and Zhang 2014). Histones can bear multiple types of modification including methylation, acetylation, phosphorylation, sumoylation, and ubiquitylation (Allis et al. 2014). They can also be replaced by variant histones with specific functions (Henikoff and Smith 2014). Any of these epigenetic modifications could qualify as an imprint. One would predict that enzymes responsible for these epigenetic modifications or an essential cofactor would be exclusively expressed in one of the two gametes, and specifically associate with one parental chromosome to copy the modification when the cell divides. However, as will be described in Section 3 on "key discoveries," only 5-methylcytosine has been clearly shown to function as the gametic imprint for imprinted genes in mammals and, to date, is the only known heritable modification.

How does a gametic imprint control imprinted expression? To understand how the imprint operates, three pieces of information are required: which parental chromosome carries the imprint, which parental chromosome carries the expressed allele of the imprinted gene, and the position of the imprinted sequence relative to the expressed or silenced allele of the imprinted gene. Using this type of approach it has been shown that gametic imprints can act on whole clusters of genes at once. These imprinted clusters contain 3-12 
imprinted genes and span from $100-3700 \mathrm{~kb}$ of genomic DNA (for more details, see http://www.mousebook.org/ catalog.php?catalog=imprinting). The majority of genes in any one cluster are imprinted protein-coding mRNA genes; however, at least one is always an imprinted lncRNA.

Because of the arrangement of imprinted genes in clusters, with some genes expressed from one parental chromosome and some from the other, it is not trivial to determine how the imprint operates. It is possible to study the effect of the imprint on single genes in the cluster, but it may prove more informative to study the effects of the imprint on the entire cluster. This will be described in more detail in Section 3. One thing, however, is clear. Nature has not chosen the simplest mechanism whereby the imprint is directed toward a promoter to preemptively silence an imprinted gene in one gamete. Instead, imprints appear, in general, to be directed toward long-range cis-acting regulators that influence the expression of multiple genes, and are located a long distance away on the same chromosome.

\section{KEY DISCOVERIES IN GENOMIC IMPRINTING}

\subsection{Imprinted Genes Control Embryonic and Neonatal Growth}

What is the function of genomic imprinting in mammals? One way to answer this question is to determine the function of known imprinted genes in vivo. This can be performed by mutating the gene sequence to impair its function using the "homologous recombination" technique. The function of many of the known imprinted genes has been determined in this fashion (for original references, see http://www .mousebook.org/catalog.php?catalog=imprinting). The most significantly represented function among imprinted genes includes genes that affect growth of the embryo, placenta, and neonate. In this category are paternally expressed imprinted genes that function as growth promoters (i.e., Igf2, Peg1, Peg3, Rasgrf1, Dlk1) and show growth retardation in embryos deficient for the gene. There are also maternally expressed imprinted genes that function as growth repressors (i.e., Igf2r, Gnas, Cdkn1c, H19, Grb10), as shown by a growth enhancement in embryos deficient for the gene. Another significant category includes genes with behavioral or neurological defects (e.g., Nesp, Ube3a, Kcnq1). These results are, at one level, disappointing because they do not identify one function for all imprinted genes. Nevertheless, these results show that the majority of imprinted genes function as embryonic or neonatal growth regulators. More interestingly, the ability to regulate growth appears to be neatly divided with maternally expressed growthregulating genes acting to repress growth of the offspring, whereas paternally expressed genes in this category act to increase growth. Moreover, numerous tested imprinted genes are active in neurological processes, some of which affect neonatal growth rate by altering maternal behavior.

\subsection{The Function of Genomic Imprinting in Mammals}

Can analyses of gene function help us understand why genes are imprinted in mammals? Assessment of genomic imprinting in different types of mammals has been informative. Placental mammals such as mice and humans, and marsupials such as opossum and wallaby, have genomic imprinting. Egg-laying mammals, such as platypus and echidna, appear to lack imprinted genes, although extensive studies have not yet been performed (Renfree et al. 2009). Placental mammals and marsupials are distinguished from egg-laying mammals by a reproductive strategy that allows the embryo to directly influence the amount of maternal resources used for its own growth. In contrast, embryos that develop within eggs are unable to directly influence maternal resources. Most invertebrates and vertebrates use an egg-laying reproductive strategy. Notably, they can also undergo parthenogenesis-a form of reproduction in which the female gamete develops into a new diploid individual without fertilization by a male gamete (note that parthenogenetic embryos arise from the duplication of the same maternal genome, whereas the gynogenetic embryos described in Fig. 2 arise from two different maternal genomes). The ability of organisms to undergo parthenogenesis most likely indicates a complete absence of genomic imprinting as it shows the paternal genome is dispensable. In mammals, however, a direct consequence of imprinted gene expression controlling fetal growth is that parthenogenesis is not possible. Both parents are necessary to produce viable offspring making mammals completely reliant on sexual reproduction to reproduce (Fig. 4). Parthenogenesis has thus not yet been observed in mammals despite claims to the contrary, although manipulating expression of the Igf2 and Dlk1 imprinted clusters has generated some rare mice with a diploid maternal genome (Kawahara et al. 2007).

Why should genomic imprinting have evolved only in some mammals, but not in vertebrates in general? Three features of genomic imprinting - the growth regulatory function of many imprinted genes, the restriction of imprinted genes to placental and marsupial mammals, and last, the necessity of the paternal genome for fetal development, provide evidence that can fit two equally attractive hypotheses.

The first hypothesis proposes that genomic imprinting evolved in response to a "parental conflict" situation 


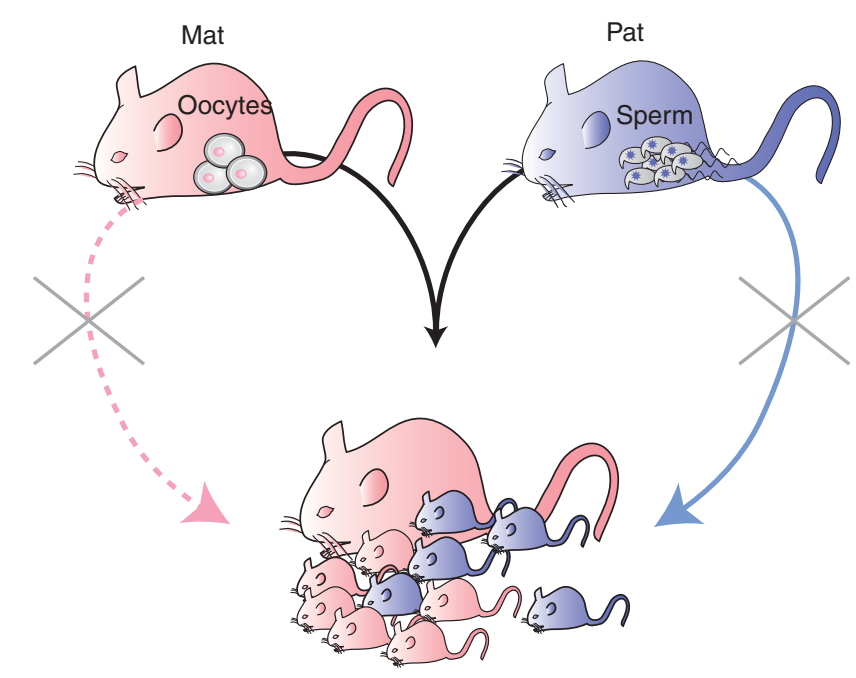

Figure 4. Imprinted genes play a role in mammalian reproduction. Mammals are diploid and reproduction requires fertilization of a haploid female egg by a haploid male sperm to recreate a diploid embryo. Only females are anatomically equipped for reproduction, but they cannot use parthenogenesis to reproduce (the possibility of which is represented by a pink dashed line) because essential imprinted genes needed for fetal growth are imprinted and silenced on maternal chromosomes. These genes are expressed only from paternal chromosomes; thus, both parental genomes are needed for reproduction in mammals. Parthenogenesis is the production of diploid offspring from two copies of the same maternal genome.

(Moore and Haig 1991). This arises from the opposing interests of the maternal and paternal genome: Embryonic growth is dependent on one parent, but influenced by an embryo whose genome comes from two parents. Paternally expressed imprinted genes are proposed to increase embryonic growth, thereby maximizing the fitness of an individual offspring bearing a particular paternal genome. Maternally expressed imprinted genes are proposed to suppress fetal growth. This would allow a more equal distribution of maternal resources to all offspring and increase transmission of the maternal genome to multiple offspring, which may have different paternal genomes.

The second hypothesis is named "trophoblast defense" (Varmuza and Mann 1994). This proposes that the maternal genome is at risk from the consequences of being anatomically equipped for internal reproduction should spontaneous oocyte activation lead to full embryonic development. Because males lack the necessary anatomical equipment for internal reproduction, they do not share the same risks should spontaneous activation of spermatozoa occur. Imprinting is thus proposed to either silence genes on the maternal chromosome that promote placental development or to activate genes that limit this process. The genes necessary for placental invasion of the maternal uterine vasculature would consequently only be expressed from a paternal genome after fertilization has occurred.

Which, if any, of these hypotheses explains the evolution of genomic imprinting in mammals? Both hypotheses indicate a role for imprinted genes in regulating the development and function of the placenta, however, neither the parental conflict nor the trophoblast defense models can provide a full explanation for all the data (Wilkins and Haig 2003). It is interesting to note that imprinted genes have also been identified in the plant endosperm, a tissue that has been compared to the placenta by virtue that it transfers nutrient resources from the parent plant to the embryo (Grossniklaus and Paro 2014). This finding strengthens arguments that genomic imprinting evolved as a means to regulate nutrient transfer between the parent and offspring, but it does not tell us why.

Fuller or alternative explanations of the function of genomic imprinting in mammals could come from two sources. The first would be to examine the function of "imprinting" across a complete gene cluster in contrast to examining the phenotype of mice lacking a single imprinted gene product. This would require an ability to reverse an imprint and generate biparental gene expression across the whole imprinted cluster. The second approach is to learn exactly how genes are imprinted. It is possible that not all genes in a cluster are deliberate targets of the imprinting mechanism and that some may just be "innocent bystanders" of the process, and their function would not be informative about the role of genomic imprinting. The existence of innocent bystander genes affected by the imprinting mechanism may satisfactorily explain the curious abundance of imprinted genes with no obvious biological function in development.

\subsection{Imprinted Genes Are Clustered and Controlled by Imprint Control Elements (ICEs)}

To date, about 150 imprinted genes have been mapped to 17 mouse chromosomes including the $\mathrm{X}$ chromosome. More than $80 \%$ of the identified imprinted genes are clustered into 16 genomic regions that contain two or more genes (Wan and Bartolomei 2008). The discovery of clusters of imprinted genes was a strong indication that a common DNA element may regulate imprinted expression of multiple genes in cis. To date, seven of the 16 imprinted clusters have been well characterized, and these are listed in Table 1 by the name of the principle imprinted mRNA gene in the cluster or after a disease association (e.g., the Pws cluster for Prader-Willi syndrome; Beaudet and Zoghbi 2014). These seven clusters contain three to 12 (or more) imprinted genes and are spread over $80-3700 \mathrm{~kb}$ of DNA. 
Table 1. Features of imprinted gene clusters in the mouse genome

\begin{tabular}{|c|c|c|c|c|c|c|}
\hline $\begin{array}{l}\text { Cluster } \\
\text { name }\end{array}$ & $\begin{array}{l}\text { Chromosome } \\
\text { mouse/human }\end{array}$ & $\begin{array}{c}\text { ICE (gametic } \\
\text { methylation imprint) }\end{array}$ & $\begin{array}{c}\text { Cluster } \\
\text { size }(k b)\end{array}$ & $\begin{array}{l}\text { Gene number } \\
\text { in cluster }\end{array}$ & $\begin{array}{c}\text { Parental } \\
\text { expression } \mathrm{M} / \mathrm{P}\end{array}$ & $\begin{array}{l}\text { IncRNA and } \\
\text { expression } \\
(\mathrm{M} \text { or } \mathrm{P})\end{array}$ \\
\hline $\operatorname{Igf2r}$ & $17 / 6$ & Region $2(\mathrm{M})$ & 490 & 4 & $\begin{array}{l}3 \mathrm{M}(\mathrm{pc}) \\
1 \mathrm{P}(\mathrm{nc})\end{array}$ & $\operatorname{Airn}(\mathrm{P})$ \\
\hline Kcnq1 & $7 / 11$ & $K v D M R 1(\mathrm{M})$ & 780 & 12 & $\begin{array}{l}11 \mathrm{M}(\mathrm{pc}) \\
1 \mathrm{P}(\mathrm{nc})\end{array}$ & Kcnq1ot1 (P) \\
\hline Pws & $7 / 15$ & Snrpn-CGI (M) & 3700 & $>8$ & $\begin{array}{l}2 \mathrm{M}(\mathrm{pc}) / \\
>7 \mathrm{P}(\mathrm{nc} \text { and } \mathrm{pc})\end{array}$ & $\begin{array}{l}\text { Ube3aas }(\mathrm{P})^{\mathrm{a}} \\
\text { Ipw }(\mathrm{P})^{\mathrm{a}} \\
\text { Zfp127as }(\mathrm{P})^{\mathrm{a}} \\
\text { PEC2 }(\mathrm{P})^{\mathrm{a}} \\
\operatorname{PEC3}(\mathrm{P})^{\mathrm{a}} \\
\operatorname{Pwcr1}(\mathrm{P})^{\mathrm{a}}\end{array}$ \\
\hline Gnas & $2 / 20$ & Nespas DMR (M) & 80 & 7 & $\begin{array}{l}2 \mathrm{M}(\mathrm{pc}) \\
5 \mathrm{P}(4 \mathrm{nc} \text { and } 1 \mathrm{pc})\end{array}$ & $\begin{array}{l}\text { Nespas }(\mathrm{P})^{\mathrm{b}} \\
\text { Exon1A }(\mathrm{P}) \\
\text { miR-296 }(\mathrm{P})^{\mathrm{b}} \\
\text { miR-298 }(\mathrm{P})^{\mathrm{b}}\end{array}$ \\
\hline Grb10 & $11 / 7$ & Meg1/Grb10 DMR (M) & 780 & 4 & $\begin{array}{l}2 \mathrm{M}(\mathrm{pc}) / \\
2 \mathrm{P}(\mathrm{pc})\end{array}$ & NI \\
\hline $\operatorname{Igf2}$ & $7 / 11$ & H19-DMD (P) & 80 & 3 & $\begin{array}{l}1 \mathrm{M}(\mathrm{nc}) / \\
2 \mathrm{P}(\mathrm{pc})\end{array}$ & H19 (M) \\
\hline Dlk1 & $9 / 14$ & IG-DMR (P) & 830 & $>5$ & $\begin{array}{l}>1 \mathrm{M}(\mathrm{nc}) / \\
4 \mathrm{P}(\mathrm{pc})\end{array}$ & $\begin{array}{l}\text { Gtl2 }(\mathrm{M})^{\mathrm{c}} \\
\text { Rian }(\mathrm{M})^{\mathrm{c}} \\
\text { Rtllas }(\mathrm{M})^{\mathrm{c}} \\
\text { Mirg }(\mathrm{M})^{\mathrm{c}} \\
\text { miRNAs }(\mathrm{M})^{\mathrm{c}} \\
\text { snoRNAs }(\mathrm{M})^{\mathrm{c}}\end{array}$ \\
\hline
\end{tabular}

Note that cluster size and number of genes in the cluster are provisional and await a genome-wide analysis of imprinted expression. Pws and Dlk1 clusters contain overlapping transcripts in which the number of distinct genes is not yet clear. Details are given in the text.

M, maternal; P, paternal; DMR, differentially methylated region; pc, protein coding; nc, noncoding RNA; NI, none identified; miRNA, micro RNA; snoRNA, small nucleolar RNAs.

${ }^{\mathrm{a}}$ May be one long lncRNA.

${ }^{\mathrm{b}}$ Part of Nespas transcript.

${ }^{\mathrm{c}}$ May be part of one or multiple lncRNAs.

A common feature of these seven clusters is the presence of a DNA sequence carrying a gametic methylation imprint that is known as a gametic DMR (differentially DNA-methylated region). A gametic DNA methylation imprint is defined as a methylation imprint established in one gamete and maintained only on one parental chromosome in diploid cells of the embryo. In five clusters (Igf2r, Kcnq1, Gnas, Grb10, and Pws), the gametic DMR has a maternal methylation imprint acquired in oogenesis, whereas in two clusters (Igf2 and Dlk1), it has a paternal methylation imprint acquired during spermatogenesis. In these examples, the gametic DMR controls imprinted expression of the whole or part of the cluster and is therefore designated as the imprint control element, or ICE, for the cluster (Barlow 2011).

Table 1 shows that each imprinted gene cluster contains multiple mRNAs and, with the exception of Grb10, at least one lncRNA. Two trends emerge. First, the imprinted protein-coding genes in each cluster are expressed, for the most part, from the same parental chromosome, whereas the lncRNA is expressed from the opposite parental chromosome (as illustrated in Fig. 5 for a maternal gametic DMR). Second, the ICE deletion causes loss of imprinted expression only when deleted from the parental allele expressing the lncRNA. Table 1 shows that in three clusters (Igf2r, Kcnq1, and Gnas) the lncRNA promoter sits in an intron of one of the imprinted mRNAs, whereas in the remaining clusters the lncRNA promoter is separated, but lies close to the imprinted mRNA genes. This close intermingling of active and silent genes in an imprinted cluster indicates that the silencing and activating mechanisms affecting imprinted genes do not spread and may be restricted to the affected gene. In particular, the fact that the promoter of a silent lncRNA can reside in the intron of an actively tran- 


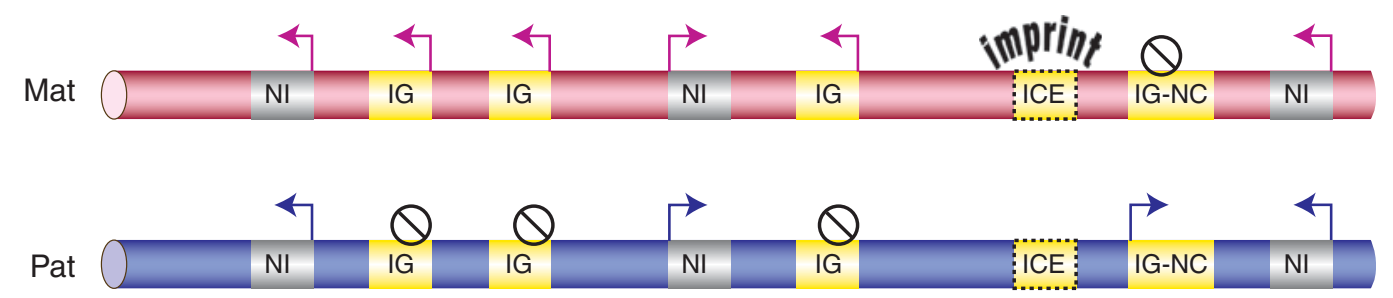

Figure 5. Imprinted genes are expressed from one parental allele and often clustered. Most imprinted genes (yellow) are found in clusters that include multiple protein-coding mRNAs (IG) and at least one noncoding RNA (IG-NC). Nonimprinted genes can also be present (NI in gray). The imprinting mechanism is cis acting and imprinted expression is controlled by an imprint control element (ICE) that carries an epigenetic imprint inherited from one parental gamete. One pair of diploid chromosomes is shown: the pink is of maternal origin and the blue of paternal origin. Arrow, expressed gene; slashed circle, repressed gene.

scribed gene indicates that silencing mechanisms may not even spread throughout the length of a gene, but may just be restricted to regulatory elements.

What is the role of the gametic DMR? Despite the fact the gametic DMRs can be maternally or paternally methylated, experiments that deleted these elements have produced broadly similar results albeit with a few interesting exceptions (Fig. 6). For three clusters (Igf2r, Kcnq1, Dlk1), experimental deletion of the methylated gametic DMR produced no effect. In contrast, deletion of the unmethylated gametic DMR eliminated parental-specific expression causing a loss of lncRNA expression in cis and biallelic mRNA expression (Lin et al. 1995; Zwart et al. 2001; Fitzpatrick et al. 2002). Two clusters (Gnas and Pws) appear to contain more than one gametic DMR and show a more complex behavior, yet they still share some similarities with the pattern presented in Figure 6 (Williamson et al. 2006). The Igf2 cluster, however, behaves differently: deletion of both the methylated and unmethylated gametic DMR causes changes in mRNA and lncRNA expression in cis (Thorvaldsen et al. 1998).

The results from the above gametic DMR deletion experiments do not at first glance indicate a common function for gametic DMRs. However, an understanding of their exact function depends on knowing the position of the DMR with respect to the imprinted genes in each cluster. In the three clusters with the simplest pattern (Igf2r, Kcnq1, and Dlk1), the gametic DMR either contains or controls expression of the lncRNA, thus deletion of this element will clearly lead to loss of lncRNA expression. The gametic

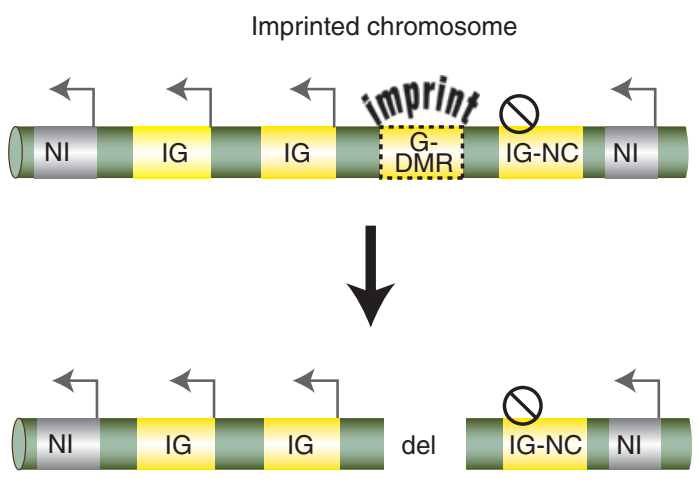

No changes in gene expression

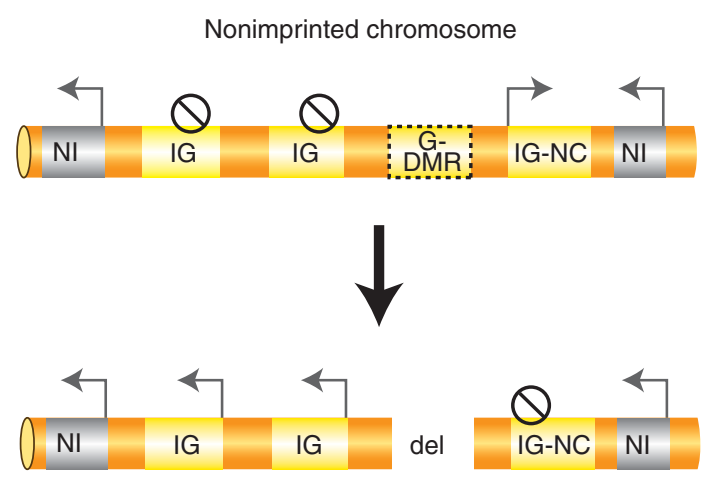

Expression resembles "imprinted" chromosome

Figure 6. Imprinted expression is regulated by gametic DMRs (G-DMR). (Left) The effect of deleting the gametic DMR from the imprinted chromosome (green). (Right) The effect of deleting the G-DMR from the nonimprinted chromosome (yellow). In many imprinted clusters (e.g., Igf2r, Kcnq1, and Dlk1), experimental deletion of the GDMR only affects the chromosome carrying the nonimprinted G-DMR. This results in a loss of repression of the imprinted protein-coding mRNA genes (IG) and a gain of repression of the imprinted lncRNA gene (IG-NC). Note that in some imprinted clusters (Igf2 and Pws) that are not illustrated here, the methylated G-DMR appears also to be required for expression of some of the imprinted mRNAs in cis. del, deleted DNA; G-DMR, gametic differentially DNA-methylated region; NG, nonimprinted gene; arrow, expressed allele; slashed circle, repressed allele; imprint, epigenetic modification leading to a change in gene expression in cis. 
DMR in the Igf2 cluster, however, does not directly promote $H 19$ transcription, but changes the interaction between Igf2 and $H 19$ and their shared enhancers, and in this way regulates their expression. Despite these differences, in general, the unmethylated gametic DMR is implicated in all six clusters as a positive regulator of lncRNA expression, and the presence of the DNA methylation imprint is associated with repression of the IncRNA. The conclusion from the data obtained from deletion of gametic DMRs clearly identifies these regions as an ICE, whose activity is regulated by DNA methylation.

\subsection{Imprinted Gene Clusters Contain at Least One IncRNA}

The majority of imprinted clusters contain an lncRNA, which is currently defined as a noncoding transcript $>200$ nucleotides (Guttman and Rinn 2012). lncRNAs, with the exception of those involved in RNA processing and translation, were previously thought to be a rarity in the mammalian genome. Now, because of the availability of the mouse and human genome sequence, transcriptome analyses have resulted in the identification of all RNA transcripts in a given cell population. This work has shown that a large part of the mammalian transcriptome is composed of lncRNAs. There are several types of mammalian noncoding RNAs (ncRNAs) that possess gene regulatory functions, including "short" ncRNAs that participate in silencing pathways (Martienssen and Moazed 2014), "longer" processed lncRNAs such as Xist, which are involved in X-chromosome activation or inactivation (Brockdorff and Turner 2014; Kuroda and Lucchesi 2014), and lncRNAs that are associated with cis or trans activation or silencing of protein-coding genes (Allis et al. 2014; essay by Rinn 2014).

What types of $\operatorname{lncRNAs}$ are associated with imprinted gene clusters? The analysis of the lncRNAs associated with the well-characterized imprinted clusters shown in Table 1 is still incomplete, highlighting some similarities, but also some differences. Three imprinted lncRNAs are unusually long mature RNAs: Airn is $108 \mathrm{~kb}$ (Lyle et al. 2000), Kcnq1ot1 is $\sim 100 \mathrm{~kb}$ (Pauler et al. 2012), and Ube3aas may be $>1000 \mathrm{~kb}$ (Landers et al. 2004). The H19 lncRNA, in contrast, is only $2.3 \mathrm{~kb}$ (Brannan et al. 1990). The Gtl2 lncRNA contains multiple alternatively spliced transcripts; however, downstream intergenic transcription has also been noted, suggesting longer transcription units are likely (Tierling et al. 2005). Nespas lncRNA is larger than can be resolved on RNA blots and the full size exceeds $27 \mathrm{~kb}$ (Robson et al. 2012). These latter lncRNAs appear to be intron poor with a low intron-exon ratio or are unspliced as mature transcripts (Seidl et al. 2006; Pandey et al. 2008). One further feature is that three imprinted lncRNAs (H19,
Ube3aas, and the Gtl2 downstream transcripts) act as host transcripts for snoRNAs (small nucleolar RNAs that direct modifications to ribosomal RNA, snRNAs, and possibly mRNAs thereby acting as posttranscription regulators) and miRNAs (micro RNAs). The snoRNAs are not directed toward the imprinted mRNA genes in the cluster and it is presently unclear if they play a role in the imprinting mechanism itself (Seitz et al. 2004). Similarly, the miRNAs in the $H 19$ and Gtl2 lncRNAs are involved in posttranscriptional repression of mRNA genes, but do not play a direct role in regulating imprinted expression of the cluster (Davis et al. 2005; Keniry et al. 2012).

Two features of imprinted lncRNAs indicate they may play a role in the silencing of the imprinted mRNA (i.e., protein-coding) genes in the cluster. The first is that the IncRNA generally shows reciprocal parental-specific expression compared to the imprinted mRNA genes (Table 1). Second, the DMR that carries the gametic methylation imprint, which controls imprinted expression of the whole cluster, overlaps with the lncRNA promoter in multiple instances (Airn region2, KvDMR1, Snrpn-CGI, and Nespas-DMR). This finding could indicate that imprints evolved to regulate the lncRNA in each imprinted cluster. This interpretation is supported by experiments that deleted the unmethylated sequence carrying the gametic DMR causing a loss of lncRNA expression concomitant with a gain of expression of imprinted mRNA genes (Fig. 6) as tested at the Igf2r, Kcnq1, Gnas, Pws, and Dlk1 clusters (Wutz et al. 1997; Bielinska et al. 2000; Fitzpatrick et al. 2002; Lin et al. 2003; Williamson et al. 2006).

Experiments that directly test the role of the lncRNA itself have now been performed for a number of loci (Airn, Nespas, Kcnq1ot1, and H19lncRNAs). These lncRNAs were analyzed by genetic manipulation of the endogenous locus. The first three loci were assayed by inserting a polyadenylation signal to truncate the lncRNA. Truncation of the 108-kb Airn lncRNA to $3 \mathrm{~kb}$ showed that the lncRNA itself is necessary to silence all three mRNA genes in the Igf2r cluster, indicating a clear regulatory role for this lncRNA (Sleutels et al. 2002). Truncation of the $\sim 100-\mathrm{kb}$ Kcnq1ot1 lncRNA to $1.5 \mathrm{~kb}$ also showed that this IncRNA was directly needed to silence all 10 mRNA genes in the larger Kcnq1 cluster (Mancini-DiNardo et al. 2006). And last, truncation of the $\sim 27-\mathrm{kb}$ Nespas lncRNA showed it was necessary to silence the overlapped Nesp gene in the Gnas imprinted cluster (Williamson et al. 2011). In contrast, precise deletion of the H19 ncRNA had no effect on imprinting in the Igf 2 cluster in endoderm tissues, although some loss of imprinting was seen in mesoderm tissue (Schmidt et al. 1999). Thus, three maternally imprinted clusters (Igf2r, Kcnq1, and Gnas) share a common lncRNA-dependent silencing mechanism, whereas the single paternally im- 
printed cluster (Igf2) so far examined uses a different, insulator-dependent model (see Section 3.6).

\subsection{The Role of DNA Methylation in Genomic Imprinting}

The identification of the first three endogenous imprinted genes in 1991 enabled investigators to study how the cell's epigenetic machinery marked an imprinted gene with its parental identity. The first and most easily testable candidate was DNA methylation, a modification in mammals that covalently adds a methyl group to the cytosine residue in CpG dinucleotides. DNA methylation is acquired through the action of de novo methyltransferases and maintained in situ each time the cell divides by the action of maintenance methyltransferases (see Li and Zhang 2014). Hence, this modification fulfills the criteria outlined in Fig. 3 for a parental identity mark or "imprint" because (1) it can be established in either the sperm or oocyte by de novo methyltransferases that act only in one gamete, (2) it can be stably propagated at each embryonic cell division by a maintenance methyltransferase, and (3) it can be erased in the germline to reset the imprint in the next generation, either by passive demethylation (DNA replication followed by the failure to undergo maintenance methylation) or through the action of a demethylating activity (possibly through conversion of 5-methylcytosine to 5-hydroxymethylcytosine by the ten-eleven translocation family of enzymes or through excision of 5-methylcytosine by the DNA repair machinery [Tan and Shi 2012; see Fig. 6 of Li and Zhang 2014]).

DNA methylation could potentially perform two different functions in genomic imprinting. It could act as the imprinting mark by being acquired de novo only by the chromosomes in one gamete. It could also serve to silence one of the parental alleles because DNA methylation is associated with gene repression ( $\mathrm{Li}$ and Zhang 2014). To determine which function it has, it is first necessary to show that DNA methylation is present only on one parental chromosome (i.e., that it is a DMR). Second, it is necessary to identify which imprinted gene in the cluster and which regulatory sequences are marked by DNA methylation. The location of methylation marks on a promoter, or on distant positive or negative regulatory elements will have different consequences for gene expression. Finally, it is necessary to identify when the DMR forms during development. If it forms during gametogenesis and is continuously maintained in place in somatic cells (known as a gametic DMR), it may serve as the imprinting mark. If, however, it is placed on the gene after the embryo has become diploid when both parental chromosomes are in the same cell (known as a somatic DMR), it is unlikely to serve as the identity mark, but may serve to maintain parentalspecific silencing.

Parental allele-specific DNA methylation has been found at most imprinted clusters that have been examined. For example, the Igf2 cluster has a gametic DMR located $2 \mathrm{~kb}$ upstream of the H19 lncRNA promoter that is methylated only in the paternal gamete and is maintained thereafter in all somatic tissues (Bartolomei et al. 1993). A similar gametic DMR was identified covering the promoter of the Airn IncRNA, present only on the silent maternal gene copy, and acquired in the female gamete (Stoger et al. 1993). Surprisingly, gametic DMRs were not identified at the promoters of the principal imprinted protein-coding genes in these clusters (respectively, Igf2 and Igf2r). Instead, the silenced Igf2 promoter is free of DNA methylation, whereas the silenced Igf2r promoter lies within a somatic DMR that is placed after fertilization (Sasaki et al. 1992; Stoger et al. 1993). Similar findings of gametic DMRs methylated on the chromosome carrying the silent copy of the imprinted lncRNA (as illustrated in Fig. 6) have been made for other well-studied imprinted gene clusters, including Pws, Kcnq1, Gnas, Dlk1, and Grb10 (Shemer et al. 1997; Liu et al. 2000; Takada et al. 2002; Yatsuki et al. 2002; Shiura et al. 2009).

Somatic DMRs are relatively rare but have been reported for some imprinted clusters, which suggests that this type of epigenetic modification plays a limited role in maintaining imprinted gene expression (Stoger et al. 1993; Moore et al. 1997; Yatsuki et al. 2002; John and Lefebvre, 2011). Deletions of gametic DMRs in mice result in complete loss of imprinting for multiple genes, thereby proving that this class of DMRs also serves as a major ICE for the whole cluster (Fig. 6) (Wutz et al. 1997; Thorvaldsen et al. 1998; Bielinska et al. 2000; Fitzpatrick et al. 2002; Lin et al. 2003; Williamson et al. 2006). In contrast, deletion of the somatic DMRs affects expression of the adjacent imprinted gene, but imprinted expression is maintained by other genes in the cluster (Constancia et al. 2000; Sleutels et al. 2003).

Genome-wide deficiency in DNA methylation caused by mutations in the Dnmt gene family underscores the essential role of DNA methylation in regulating imprinted gene expression. Mutations in the de novo DNA methyltransferase Dnmt3a, the DNA methyltransferase stimulatory factor Dmnt3L, or the Dnmt1 maintenance DNA methyltransferase generate DNA methylation deficient embryos that show alterations in imprinted gene expression. The type of perturbations shown for four imprinted clusters (Igf2, Igf2r, Kcnq1, and Dlk1) indicates that DNA methylation is generally acting to suppress the action of the gametic DMR. Thus, in the absence of DNA methylation, the gametic DMR cannot function appropriately (i.e., cannot silence the lncRNA). As a consequence, the lncRNA is ab- 
errantly expressed and several imprinted protein-coding genes, including Igf2, Igf2r, Kcnq1, and Dlk1, become repressed on both parental chromosomes. This indicates that these mRNA genes require epigenetic modification of a cis-regulatory element to be expressed. Notably, the H19 lncRNA that is normally only expressed on the chromosome carrying the unmethylated gametic DMR becomes expressed on both parental chromosomes. Some exceptions to this general pattern have been reported for genes that show imprinted expression only in the placenta (Lewis et al. 2004).

Are other types of epigenetic modification used as gametic imprints? Given the sheer abundance of epigenetic mechanisms acting to modify genetic information in the mammalian genome, DNA methylation is unlikely to be the only imprinting mechanism. Histone modifications that affect chromatin activity states are also likely candidates for parental imprints because they could fulfill many of the prerequisites shown in Fig. 3. In one example, the Polycomb group protein known as EED (part of the PRC2 complex that catalyzes methylation of $\mathrm{H} 3 \mathrm{~K} 27$, i.e., histone $\mathrm{H} 3$ at lysine 27) has been shown to affect a few paternally repressed genes in the placenta. The effects of Eed mutation on genomic imprinting, however, are relatively minor compared to that of DNA methylation (Mager et al. 2003). In another example, the EHMT2 histone methyltransferase acting specifically on $\mathrm{H} 3 \mathrm{~K} 9$ is required to repress a few imprinted genes, but also only in the placenta (Nagano et al. 2008). Thus, evidence to date suggests that histone modifications and modifying enzymes play a minor role in genomic imprinting.

Although much is known about the identity and epigenetic modifications of gametic DMRs, much less is known about how these sequences are chosen for methylation in the gametes. To date, many more maternally than paternally methylated gametic DMRs have been identified (Bartolomei and Ferguson-Smith 2011). The maternally methylated DMRs are methylated during oocyte growth and the paternally methylated DMRs are methylated prenatally in prospermatogonia (Fig. 7) (Lucifero et al. 2002). For maternal gametic DMRs, a sequence comparison of known gametic DMRs reveals no striking sequence conservation although some contain a series of direct repeats that may adopt a secondary structure that attracts DNA methylation (Neumann et al. 1995). The tandem direct repeats in the Igf2r cluster gametic DMR have, for instance, been shown to be essential for oocyte-specific DNA methylation (Koerner et al. 2012). Those in the Kcnq1 cluster gametic DMR, however, are not essential (Mancini-DiNardo et al. 2006). Another feature of maternal DMRs is that they are markedly $\mathrm{CpG}$ rich compared to the remainder of the genome. One idea for how these regions are recognized comes from the structural analysis of the complexed carboxy-terminal domains of DNMT3A and DNMT3L, which was obtained by $\mathrm{X}$-ray crystallography (Jia et al. 2007). A tetrameric complex consisting of these two enzymes preferentially methylates a pair of CpGs that are 8-10 base pairs apart (Cheng 2014). Such spacing is found in maternally methylated, but not in paternally methylated imprinted loci. This CpG spacing, however, is widespread in the genome, questioning the specificity of such a mechanism or indicating that additional features are required (Ferguson-Smith and Greally 2007). Additional specificity has been suggested by the demonstration that DNMT3L interacts with the amino terminus of histone $\mathrm{H} 3$ if the $\mathrm{H} 3 \mathrm{~K} 4$ residue is unmethylated, and promotes local DNA methylation ( for more detail, see Ooi et al. 2007; Cheng 2014). Another factor contributing to the specificity of de novo DNA methylation at DMRs in the oocyte is transcription across differentially methylated regions (Chotalia et al. 2009). Importantly, only protein-coding transcripts traversing the germline ICEs are thought to be involved in DNA methylation establishment. Although it is, as yet, unclear how this transcription may be attracting the DNA methylation machinery, it has been suggested that transcription across ICEs is required to establish or maintain open chromatin domains that are permissive for the establishment of DNA methylation. To investigate and define the mechanism further, it will be necessary to describe the temporal relationship between transcription and de novo DNA methylation in greater detail. Nevertheless, CpG spacing, posttranslational histone modifications, and transcription in oocytes could provide a starting point for the acquisition of maternal-specific DNA methylation imprints.

There is far less information regarding how paternalspecific DNA methylation imprints are established in the male germline. Nevertheless, early experiments suggest there could be some similarities with the female germline. It has recently been shown that high transcriptional readthrough, predominantly from one strand, is detected at two paternal gametic DMRs in primordial germ cells, H19DMD and IG-DMR, at the time of imprint establishment (Henckel et al. 2011). It also appears that maternal gametic DMRs, which are protected from DNA methylation, are enriched for $\mathrm{H} 3$ lysine 4 trimethylation (H3K4me3) in male primordial germ cells.

One of the most mysterious questions in genomic imprinting is how the DNA methylation marks at imprinted genes escape the genome-wide reprogramming that occurs after fertilization, including the DNA demethylation that occurs in the preimplantation embryo and the subsequent wave of de novo DNA methylation (Fig. 7) (see Morgan et al. 2005; Fig. 3 in Li and Zhang 2014). It is likely that a combination of cis-acting sequences and trans-acting factors are 


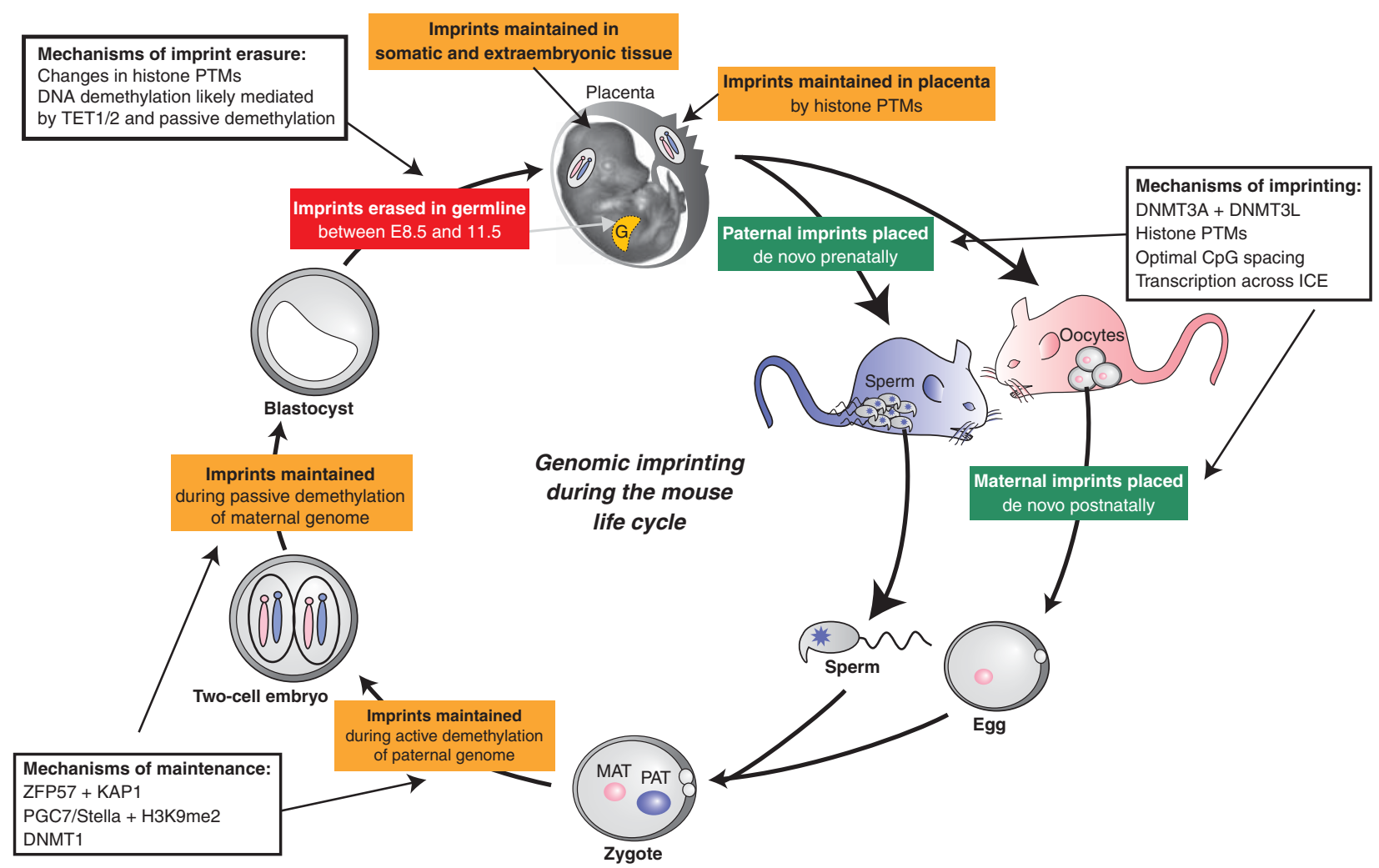

Figure 7. Establishment, maintenance, and erasure of genomic imprints in mouse development. In the germline, primordial germ cells (PGCs) undergo multiple changes in chromatin structure and DNA demethylation during migration into the genital ridge (gonad). Imprints are then acquired in a sex-specific manner in the germline (green shading). DNA methylation is targeted specifically to paternally and maternally DNA-methylated ICEs—prenatally in prospermatogonia and postnatally during oocyte maturation. These imprints are maintained despite global changes in DNA methylation after fertilization (orange shading): active demethylation of the paternal genome in the zygote and passive maternal demethylation in the preimplantation embryo. Candidates for protection of methylation regions include ZFP57 and PGC7/STELLA. De novo DNA methylation of the genome begins at the morula stage, during which time unmethylated alleles of imprinted genes must be protected. These imprints are maintained in somatic cells throughout the lifetime of the organism, whereas imprinting in extraembryonic tissues is thought to be less dependent on maintenance of DNA methylation. In the germline, imprints are erased and reset for the next generation (red shading). PTM, post-translational modification; MAT, maternal genome; PAT, paternal genome.

mediating the protection. One maternal factor, PGC7/ STELLA, appears to have a general role in maintaining DNA methylation in the early mouse embryo through interactions with H3K9me2 (Nakamura et al. 2012). However, a factor that may be more specific for imprinted genes is ZFP57. Studies have shown that ZFP57 mutationsidentified in transient neonatal diabetes patients are associated with defects in DNA methylation at multiple imprinted loci (Mackay et al. 2008). Additionally, Zfp57 null mice show embryonic lethality and loss of imprinting at many (but not all) loci ( $\mathrm{Li}$ et al. 2008). More recently, it has been shown that ZFP57 binds to cofactor KAP1, which can then recruit other epigenetic regulators (Quenneville et al. 2011). Thus, sequence- and DNA methylation-dependent binding of ZFP57 could act as an anchor to specify allelic binding of
KAP1, which would subsequently recruit other major repressive epigenetic regulators such as SETDB1, HP1, DNMT1, DNMT3A, and DNMT3B to the heterochromatic, silenced allele at imprinted loci. It is possible that other yet-to-be-identified proteins also maintain DNA methylation at imprinted loci in the early embryo.

\subsection{Two Types of cis-Acting Silencing Identified in Imprinted Gene Clusters}

Currently, two major classes of cis-acting silencing mechanisms are hypothesized to govern imprinting at various clusters: the insulator model applicable to the Igf2 cluster and the lncRNA-mediated silencing model applicable to the Igf2r and Kcnq1 clusters. Although not yet completely 
defined, most of the clusters in Table 1 incorporate aspects of one of the two models. The breakthrough that led to the definition of the insulator model at the Igf2 locus was the deletion of the gametic DMR (H19-DMD) that is located $2 \mathrm{~kb}$ upstream of the start of $\mathrm{H} 19$ transcription and $80 \mathrm{~kb}$ downstream of Igf2 (Fig. 8) (Thorvaldsen et al. 1998). When deleted, H19 and Igf2 showed a loss of imprinting regardless of whether the deletion was inherited maternally or paternally, identifying this DMR as an ICE. It was sub- sequently shown that this ICE bound CTCF, a protein shown to mediate insulator activity at the beta-globin locus, and that the ICE itself functioned as an insulator (Bell and Felsenfeld 2000; Hark et al. 2000). In this context, an insulator is defined as an element that blocks enhancer and promoter interactions when placed between them. Thus, the model for imprinted gene expression at this locus is as follows: on the maternal allele, CTCF binds to the ICE and blocks the access of Igf2 and Ins 2 to enhancers shared with

A Insulator model-Igf2 cluster

Mat

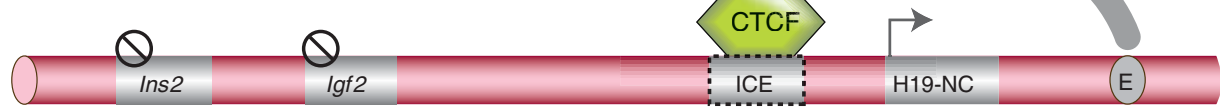

Insulator blocks mRNA activation; enhancers activate ncRNA.

Pat

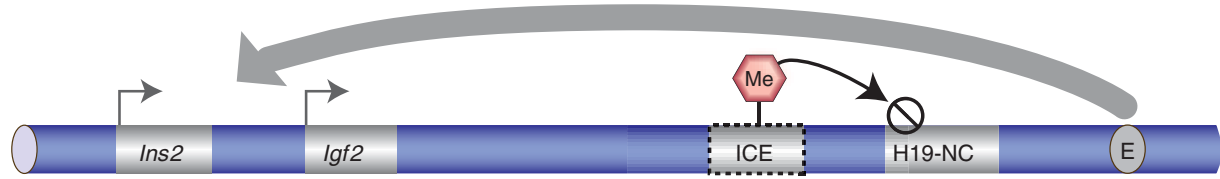

Paternal $\mathrm{CH}_{3}$ methyl imprint silences ICE and ncRNA; enhancers activate mRNAs.

B IncRNA Model-Igf2r cluster

Mat

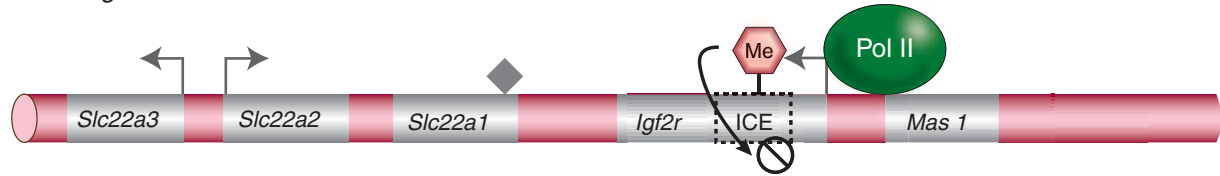

Maternal $\mathrm{CH}_{3}$ methyl imprint silences ICE; mRNAs expressed.

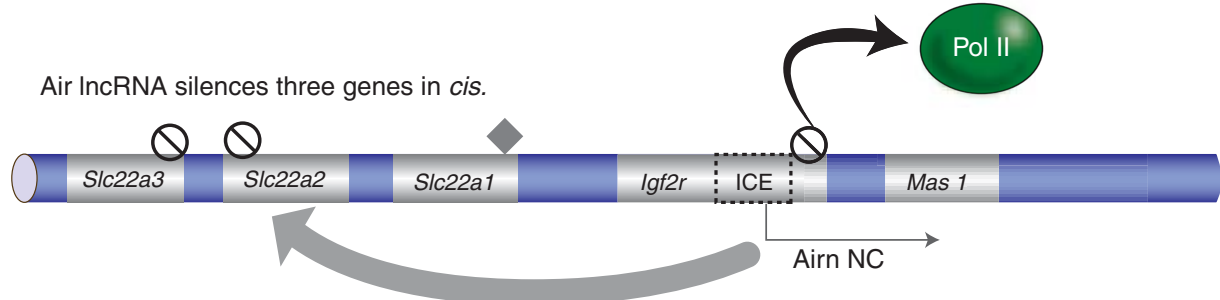

Figure 8. Two cis-acting silencing mechanisms at imprinted gene clusters. (A) Insulator model for the Igf2 cluster. The expression pattern for endoderm is shown. On the maternal chromosome, the unmethylated ICE binds the CTCF protein and forms an insulator that prevents the common endoderm enhancers (E) from activating Igf2 and Ins2. Instead the enhancers activate the nearby $\mathrm{H} 19 \mathrm{lncRNA}$ promoter. On the paternal chromosome, the methylated ICE cannot bind CTCF and an insulator does not form; hence the Igf2 and Ins 2 mRNA genes are expressed only on this chromosome. The H19 lncRNA is methylated, most likely because of spreading from the 2-kb distant methylated ICE, and silenced. $(B) \operatorname{lncRNA}$ model for the Igf2 $r$ cluster. The expression pattern for placenta is shown. On the maternal chromosome, the methylated ICE contains the Airn lncRNA promoter that is directly silenced by the DNA methylation imprint. The Igf2r, Slc22a2, and Slc22a3 mRNA genes are expressed only on this chromosome. Mas1 and Slc22a1 are not expressed in placenta (filled diamond). On the paternal chromosome, the Airn lncRNA promoter lying in the unmethylated ICE is expressed and silences Igf2r (in part by kicking off RNA polymerase II), Slc22a2, and Slc22a3 in cis. Note that in both models, the DNA methylation imprint silences the lncRNA and permits mRNA expression. ICE, imprint control element; gray arrow, expressed allele of an imprinted gene; slashed circle, repressed allele of an imprinted gene; thick gray arrows, long distance effect in cis. 
the H19 lncRNA that are located downstream of the three genes. This thereby allows $H 19$ exclusive access to the enhancers (Fig. 8). On the paternal allele, the ICE acquires DNA methylation in the male germline, preventing CTCF from binding to it. Thus, on the paternal chromosome, Igf2 and Ins 2 interact with the enhancers and are expressed from this chromosome. The presence of DNA methylation on the paternal ICE leads to secondary methylation of the H19 promoter by an unknown mechanism and it becomes silenced on the paternal chromosome. Although the insulator model is widely accepted, it is unclear how the insulator acts at this locus. One of the most widely held views is that CTCF interacts with DNA molecules in cis to insulate genes through the formation of chromatin loops (for more detail, see Dekker and Misteli 2014). Moreover, it has been shown that cohesin interacts with CTCF to form these loops (Nativio et al. 2009). The involvement of CTCF in the insulator model has led to the identification of CTCF binding sites at other imprinted genes such as Rasgrf1, Grb10, and Kcnq1ot1, indicating that the insulator model may operate in other imprinted clusters.

The lncRNA class of imprinting model may, however, be more common. The breakthrough that led to the identification of functional ncRNAs in imprinted clusters was an experiment that truncated the $108-\mathrm{kb}$ Airn $\operatorname{lncRNA}$ to $3 \mathrm{~kb}$ (Sleutels et al. 2002). This shortened lncRNA retained imprinted expression and the Airn promoter retained imprinted DNA methylation-yet silencing of all three mRNA genes in the Igf2rcluster was lost (Fig. 8). IncRNA-mediated silencing has also now been shown to operate at the Kcnq1 cluster (Mancini-DiNardo et al. 2006), although in a tissuespecific manner, suggesting that another mechanism such as one that uses insulators may also be involved at this cluster (Shin et al. 2008), and in the Gnas imprinted cluster (Williamson et al. 2011). At this time it is not precisely known how lncRNAs silence genes but many models are possible. Two possibilities arise from the sense-antisense overlap between an mRNA and the lncRNA that occurs in each cluster. The first possibility is that double-stranded RNA can form between the mRNA and lncRNA and induce RNA-interference (RNAi) (described in Martienssen and Moazed 2014). Absence of the RNAi machinery, however, does not affect imprinted expression in the Kcnq1 cluster (Redrup et al. 2009). Thus, a second possibility is that this sense-antisense overlap causes a form of transcriptional interference of a promoter or an enhancer, which affects transcription from the mRNA promoter (Pauler et al. 2012). In this case, the first event could be silencing of the overlapped promoter or enhancer followed by accumulation of repressive chromatin that can spread and induce transcriptional gene silencing throughout the cluster. Evidence for this model comes from a series of recombinant endogenous chromosomes generated at the Igf2r/Airn locus in ES (embryonic stem) cells (Latos et al. 2012). The onset of allele-specific expression at this locus in the embryo can be recapitulated by ES cell differentiation, in which Igf2r is initially biallelically expressed, but the initiation of Airn expression results in Igf2r imprinting (Latos et al. 2009). To test whether Airn transcription or the lncRNA itself was required for Igf2r silencing, Airn was shortened to different lengths, with the result that silencing only required Airn transcription overlap of the Igf2r promoter, which interferes with RNA polymerase II recruitment (Latos et al. 2012). This model suggests that Airn acts predominantly through its transcription rather than as an lncRNA.

It is, however, also possible that imprinted lncRNAs act by coating the local chromosomal region and directly recruit repressive chromatin proteins to the imprinted cluster, in a manner similar to that described for the action of the Xist lncRNA in X-chromosome inactivation (Brockdorff and Turner 2014). Evidence for a function of the lncRNA in recruitment of histone posttranslational modification machinery comes from experiments in placental tissues. RNA fluorescence in situ hybridization experiments showed that Airn and Kcnq1ot1 form RNA clouds at their site of transcription (Nagano et al. 2008; Pandey et al. 2008; Terranova et al. 2008; Redrup et al. 2009). Terranova and colleagues show that these long ncRNAs are associated with a repressive histone compartment and Polycomb group proteins (Terranova et al. 2008). This nuclear compartment is also devoid of RNA polymerase II and exists in a three-dimensionally contracted state. Other studies on the Airn lncRNA go further in suggesting that the lncRNAs actively recruit repressive histone modifications (Nagano et al. 2008), but only in the placenta. In this latter case, Airn was shown to actively recruit the EHMT2 H3K9 methyltransferase. This resulted in the paternal-specific silencing of the Slc22a3 gene but not the Igf2 $r$ gene. These experiments indicate that lncRNAmediated silencing of imprinted genes may depend on different downstream mechanisms.

Importantly, other mechanisms of imprinted gene regulation are likely. For example, Wood and colleagues described a new imprinted locus (H13) in which alternative polyadenylation sites are used in an allele-specific manner (Wood et al. 2008). The H13 gene contains a maternally methylated internal CpG island that acquires DNA methylation in oocytes (it has not been tested for ICE activity yet). Hypermethylation of this $\mathrm{CpG}$ island ensures synthesis of the full length and functional $\mathrm{H} 13$ gene transcript from the maternal chromosome. Experiments showed that the unmethylated $\mathrm{CpG}$ island on the paternal allele allowed transcription from the promoter for the Mcts2 retrogene. Mcts2 expression, in turn, correlates with the premature polyadenylation of $\mathrm{H} 13$ and, hence, expression 
of truncated H13 transcripts. This locus raises the possibility that other less widely used mechanisms of genomic imprinting will be identified once the full catalog of imprinted genes is elucidated.

\section{GENOMIC IMPRINTING - A MODEL FOR MAMMALIAN EPIGENETIC REGULATION}

Studying genomic imprinting has an advantage over other mammalian epigenetic gene regulation models because both the active and inactive parental allele reside in the same nucleus and are exposed to the same transcriptional environment (Bartolomei 2009; Barlow 2011). As a result, any epigenetic difference between the two parental alleles is more likely to correlate to their transcriptional state in contrast to "before and after" epigenetic systems, in which epigenetic changes may also reflect the altered differentiation state of the cell. The presence of both the active and silent parental allele in the same nucleus makes genomic imprinting an ideal system to study epigenetic gene regulation. At the same time, it imposes a difficulty because it is necessary to first distinguish between the parental alleles so that specific features associated with gene activity and silencing can be attributed to the right parental allele. This difficulty has been largely overcome in the mouse by the development of model systems that allow the maternal and paternal chromosomes to be distinguished (Fig. 1). Despite the fact that epigenetic gene regulatory mechanisms are highly conserved in evolution, there are likely to be differences that relate to the type of genome organization for each organism. The mammalian genome shows an unusual organization that intersperses genes with high copy number repeats (also known as transposable elements). This greatly increases the length of most genes as well as the distance between adjacent genes. This contrasts with other model organisms such as yeast, nematodes, plants, and Drosophila, whose genomes show a tendency toward remaining repeat-free or, at least to separate repeats from genes (for organismal comparisons, see Rabinowicz et al. 2003; Fig. 19 of Allis et al. 2014). How can genomic imprinting contribute to an understanding of mammalian epigenetics? Although the characterization of imprinted gene clusters is far from complete, they clearly have the potential to provide information about how genes are controlled in local regions or domains. To date, imprinted gene clusters have already provided examples of cis-acting DNA sequences that are regulated by DNA methylation, genes that are silenced by default in the mammalian genome and require epigenetic activation to be expressed, longrange regulatory elements that can act as insulators, and unusual lncRNAs that silence large domains of genes in cis. Time will tell whether these types of epigenetic regulatory mechanisms are unique to imprinted clusters or whether they can also be found regulating expression of nonimprinted genes in the mammalian genome.

\section{FUTURE DIRECTIONS}

Genomic imprinting has been the focus of intense interest since the discovery of the first imprinted genes in mammals in 1991. Whereas early experiments relied on molecular and genetic strategies to identify imprinted genes, highthroughput technology on polymorphic individuals is allowing the complete determination of imprinted genes (Deveale et al. 2012) and regions containing parental-specific DNA methylation (Xie et al. 2012). These experiments are indicating that most genes showing ubiquitous imprinted expression have already been identified (http:// www.mousebook.org/catalog.php?catalog=imprinting). However, it is possible that some genes showing tissuespecific imprinted expression remain to be identified (Prickett and Oakey 2012). Some questions still await conclusive answers, particularly those concerning why mammals alone among vertebrates use imprinted genes to regulate embryonic and neonatal growth. This lack of knowledge contrasts with the extensive progress during the intervening 20 years on elucidating the epigenetic mechanisms controlling imprinted expression in mammals. From this information, we think we understand the general principles of how the imprinting mechanism operates at imprinted gene clusters, although all the details are still not clear. At this stage, it is clear that genomic imprinting uses the cell's normal epigenetic machinery to regulate parental-specific expression, and that everything is set in motion by restricting this machinery in the gamete to just one parental allele. Although there are general similarities in the mechanism controlling imprinted expression at different gene clusters, it is not yet understood how many variants of this mechanism exist in the mammalian genome. In the future, it will also be of interest to determine to what degree nonimprinted genes are controlled by the epigenetic mechanisms described for imprinted gene clusters. Ultimately, transferring this knowledge for therapeutic use in humans, for example, by inducing re-expression of the silent parental alleles in patients with the PraderWilli and Angelman syndromes to ameliorate their symptoms would be of great benefit (for further discussion, see Huang et al. 2011; Beaudet and Zoghbi 2014). An understanding of the way the cell controls epigenetic information is of increasing importance, with the realization that epigenetic regulation can also be disturbed in cancers (Jones and Baylin 2014), in assisted reproductive technologies and also in the aging process (Rando and Chang 2012; Berger and Sassone-Corsi 2014). An improved understand- 
ing of genomic imprinting will undoubtedly continue to provide an important model to discover how the mammalian genome uses epigenetic mechanisms to regulate gene expression.

\section{ACKNOWLEDGMENTS}

We are grateful to the past and present members of the Barlow and Bartolomei laboratories for discussions and debates on the ideas presented here. We apologize that limitations on the number of references prevented citation of all original data.

\section{REFERENCES}

* Reference is also in this collection.

* Allis CD, Jenuwein T, Reinberg D. 2014. Overview and concepts. Cold Spring Harb Perspect Biol doi: 10.1101/cshperspect.a018739.

Barlow DP. 2011. Genomic imprinting: A mammalian epigenetic discovery model. Annu Rev Genet 45: 379-403.

Barlow DP, Stoger R, Herrmann BG, Saito K, Schweifer N. 1991. The mouse insulin-like growth factor type- 2 receptor is imprinted and closely linked to the Tme locus. Nature 349 : $84-87$.

Bartolomei MS. 2009. Genomic imprinting: Employing and avoiding epigenetic processes. Genes Dev 23: 2124-2133.

Bartolomei MS, Ferguson-Smith AC. 2011. Mammalian genomic imprinting. Cold Spring Harb Perspect Biol doi: 10.1101/cshperspect. a002592.

Bartolomei MS, Webber AL, Brunkow ME, Tilghman SM. 1993. Epigenetic mechanisms underlying the imprinting of the mouse H19 gene. Genes Dev 7: 1663-1673.

Bartolomei MS, Zemel S, Tilghman SM. 1991. Parental imprinting of the mouse H19 gene. Nature 351: 153-155.

Barton SC, Surani MA, Norris ML. 1984. Role of paternal and maternal genomes in mouse development. Nature 311: 374-376.

* Beaudet A, Zoghbi H. 2014. Epigenetics and human disease. Cold Spring Harb Perspect Biol doi: 10.1101/cshperspect.a019497.

Bell AC, Felsenfeld G. 2000. Methylation of a CTCF-dependent boundary controls imprinted expression of the Igf2 gene. Nature 405: 482-485.

* Berger S, Sassone-Corsi P. 2014. Metabolic signaling to chromatin. Cold Spring Harb Perspect Biol doi: 10.1101/cshperspect.a019463.

Bielinska B, Blaydes SM, Buiting K, Yang T, Krajewska-Walasek M, Horsthemke B, Brannan CI. 2000. De novo deletions of SNRPN exon 1 in early human and mouse embryos result in a paternal to maternal imprint switch. Nat Genet 25: 74-78.

Brannan CI, Dees EC, Ingram RS, Tilghman SM. 1990. The product of the H19 gene may function as an RNA. Mol Cell Biol 10: 28-36.

* Brockdorff N, Turner B. 2014. Dosage compensation in mammals. Cold Spring Harb Perspect Biol doi: 10.1101/cshperspect.a019406.

Cattanach BM, Kirk M. 1985. Differential activity of maternally and paternally derived chromosome regions in mice. Nature 315: 496-498.

Chaillet JR, Bader DS, Leder P. 1995. Regulation of genomic imprinting by gametic and embryonic processes. Genes Dev 9: 1177-1187.

Chandra HS, Nanjundiah V. 1990. The evolution of genomic imprinting. Dev Suppl 1990: 47-53.

* Cheng X. 2014. Structural and functional linkage of DNA and histone methylation. Cold Spring Harb Perspect Biol doi: 10.1101/cshperspect. a018747.

Chotalia M, Smallwood SA, Ruf N, Dawson C, Lucifero D, Frontera M, James K, Dean W, Kelsey G. 2009. Transcription is required for estab- lishment of germline methylation marks at imprinted genes. Genes Dev 23: 105-117.

Constancia M, Dean W, Lopes S, Moore T, Kelsey G, Reik W. 2000. Deletion of a silencer element in Igf2 results in loss of imprinting independent of H19. Nat Genet 26: 203-206.

Cooper DW, VandeBerg JL, Sharman GB, Poole WE. 1971. Phosphoglycerate kinase polymorphism in kangaroos provides further evidence for paternal X inactivation. Nat New Biol 230: 155-157.

Crouse HV, Brown A, Mumford BC. 1971. Chromosome inheritance and the problem of chromosome "imprinting" in Sciara (Sciaridae, Diptera). Chromosoma 34: 324-398.

Davis E, Caiment F, Tordoir X, Cavaille J, Ferguson-Smith A, Cockett N, Georges M, Charlier C. 2005. RNAi-mediated allelic trans-interaction at the imprinted Rtl1/Peg11 locus. Curr Biol 15: 743-749.

DeChiara TM, Robertson EJ, Efstratiadis A. 1991. Parental imprinting of the mouse insulin-like growth factor II gene. Cell 64: 849-859.

* Dekker J, Misteli T. 2014. Long-range chromatin interactions. Cold Spring Harb Perspect Biol doi: 10.1101/cshperspect.a019356.

Deveale B, van der Kooy D, Babak T. 2012. Critical evaluation of imprinted gene expression by RNA-seq: A new perspective. PLoS Genet 8: e1002600.

Ferguson-Smith AC, Greally JM. 2007. Epigenetics: Perceptive enzymes. Nature 449: 148-149.

Ferguson-Smith AC, Cattanach BM, Barton SC, Beechey CV, Surani MA. 1991. Embryological and molecular investigations of parental imprinting on mouse chromosome 7. Nature 351: 667-670.

Fitzpatrick GV, Soloway PD, Higgins MJ. 2002. Regional loss of imprinting and growth deficiency in mice with a targeted deletion of KvDMR1. Nat Genet 32: 426-431.

* Grossniklaus U, Paro R. 2014. Transcriptional silencing by Polycomb group proteins. Cold Spring Harb Perspect Biol doi: 10.1101/ cshperspect.a019331.

Guttman M, Rinn JL. 2012. Modular regulatory principles of large non-coding RNAs. Nature 482: 339-346.

Hark AT, Schoenherr CJ, Katz DJ, Ingram RS, Levorse JM, Tilghman SM. 2000. CTCF mediates methylation-sensitive enhancer-blocking activity at the H19/Igf2 locus. Nature 405: 486-489.

Henckel A, Chebli K, Kota SK, Arnaud P, Feil R. 2011. Transcription and histone methylation changes correlate with imprint acquisition in male germ cells. EMBO J 31: 606-615.

* Henikoff S, Smith M. 2014. Histone variants and epigenetics. Cold Spring Harb Perspect Biol doi: 10.1101/cshperspect.a019364.

Hoppe PC, Illmensee K. 1982. Full-term development after transplantation of parthenogenetic embryonic nuclei into fertilized mouse eggs. Proc Natl Acad Sci 79: 1912-1916.

Huang HS, Allen JA, Mabb AM, King IF, Miriyala J, Taylor-Blake B, Sciaky N, Dutton JW Jr, Lee HM, Chen X, et al. 2011. Topoisomerase inhibitors unsilence the dormant allele of Ube3a in neurons. Nature 481: $185-189$.

Jia D, Jurkowska RZ, Zhang X, Jeltsch A, Cheng X. 2007. Structure of Dnmt3a bound to Dnmt3L suggests a model for de novo DNA methylation. Nature 449: 248-251.

John RM, Lefebvre L. 2011. Developmental regulation of somatic imprints. Differentiation 81: 270-280.

Johnson DR. 1974. Hairpin-tail: A case of post-reductional gene action in the mouse egg. Genetics 76: 795-805.

* Jones P, Baylin S. 2014. Epigenetic determinants of cancer. Cold Spring Harb Perspect Biol doi: 10.1101/cshperspect.a019505.

Kawahara M, Wu Q, Takahashi N, Morita S, Yamada K, Ito M, FergusonSmith AC, Kono T. 2007. High-frequency generation of viable mice from engineered bi-maternal embryos. Nat Biotechnol 25: 1045-1050.

Keniry A, Oxley D, Monnier P, Kyba M, Dandolo L, Smits G, Reik W. 2012. The H19 lincRNA is a developmental reservoir of miR-675 that suppresses growth and Igf2r. Nat Cell Biol 14: 659-665.

Koerner MV, Pauler FM, Hudson QJ, Santoro F, Sawicka A, Guenzi PM, Stricker SH, Schichl YM, Latos PA, Klement RM, et al. 2012. A down- 
stream CpG island controls transcript initiation and elongation and the methylation state of the imprinted Airn macro ncRNA promoter. PLoS Genet 8: e1002540.

* Kuroda M, Lucchesi J. 2014. Dosage compensation in Drosophila. Cold Spring Harb Perspect Biol doi: 10.1101/cshperspect.a019398.

Landers M, Bancescu DL, Le Meur E, Rougeulle C, Glatt-Deeley H, Brannan C, Muscatelli F, Lalande M. 2004. Regulation of the large (approximately $1000 \mathrm{~kb}$ ) imprinted murine Ube3a antisense transcript by alternative exons upstream of Snurf/Snrpn. Nucleic Acids Res 32: 3480-3492.

Latos PA, Pauler FM, Koerner MV, Senergin HB, Hudson QJ, Stocsits RR, Allhoff W, Stricker SH, Klement RM, Warczok KE, et al. 2012. Airn transcriptional overlap, but not its lncRNA products, induces imprinted Igf2r silencing. Science 338: 1469-1472.

Latos PA, Stricker SH, Steenpass L, Pauler FM, Huang R, Senergin SH, Regha K, Koerner MV, Warczok KE, Unger C, et al. 2009. An in vitro ES cell imprinting model shows that imprinted expression of the Igf2r gene arises from an allele-specific expression bias. Development 136: 437-448.

Lewis A, Mitsuya K, Umlauf D, Smith P, Dean W, Walter J, Higgins M, Feil R, Reik W. 2004. Imprinting on distal chromosome 7 in the placenta involves repressive histone methylation independent of DNA methylation. Nat Genet 36: 1291-1295.

Li X, Ito M, Zhou F, Youngson N, Zuo X, Leder P, Ferguson-Smith AC. 2008. A maternal-zygotic effect gene, $Z f p 57$, maintains both maternal and paternal imprints. Dev Cell 15: 547-557.

* Li E, Zhang Y. 2014. DNA methylation in mammals. Cold Spring Harb Perspect Biol doi: 10.1101/cshperspect.a019133.

Lin MS, Zhang A, Fujimoto A. 1995. Asynchronous DNA replication between 15q11.2q12 homologs: Cytogenetic evidence for maternal imprinting and delayed replication. Hum Genet 96: 572-576.

Lin SP, Youngson N, Takada S, Seitz H, Reik W, Paulsen M, Cavaille J, Ferguson-Smith AC. 2003. Asymmetric regulation of imprinting on the maternal and paternal chromosomes at the Dlk1-Gtl2 imprinted cluster on mouse chromosome 12. Nat Genet 35: 97-102.

Liu J, Litman D, Rosenberg MJ, Yu S, Biesecker LG, Weinstein LS. 2000. A GNAS1 imprinting defect in pseudohypoparathyroidism type IB. J Clin Invest 106: 1167-1174.

Lucifero D, Mertineit C, Clarke HJ, Bestor TH, Trasler JM. 2002. Methylation dynamics of imprinted genes in mouse germ cells. Genomics 79: $530-538$.

Lyle R, Watanabe D, te Vruchte D, Lerchner W, Smrzka OW, Wutz A, Schageman J, Hahner L, Davies C, Barlow DP. 2000. The imprinted antisense RNA at the Igf2r locus overlaps but does not imprint Mas1. Nat Genet 25: 19-21.

Mackay DJ, Callaway JL, Marks SM, White HE, Acerini CL, Boonen SE, Dayanikli P, Firth HV, Goodship JA, Haemers AP, et al. 2008. Hypomethylation of multiple imprinted loci in individuals with transient neonatal diabetes is associated with mutations in ZFP57. Nat Genet 40: 949-951.

Mager J, Montgomery ND, de Villena FP, Magnuson T. 2003. Genome imprinting regulated by the mouse Polycomb group protein Eed. Nat Genet 33: 502-527.

Mancini-DiNardo D, Steele JS, Levorse JM, Ingram RS, Tilghman SM. 2006. Elongation of the Kcnqot1 transcript is required for genomic imprinting of neighboring genes. Genes Dev 20: 1268-1282.

* Martienssen R, Moazed D. 2014. RNAi and heterochromatin assembly. Cold Spring Harb Perspect Biol doi: 10.1101/cshperspect.a019323.

McGrath J, Solter D. 1984a. Completion of mouse embryogenesis requires both the maternal and paternal genomes. Cell 37: 179-183.

McGrath J, Solter D. 1984b. Maternal Thp lethality in the mouse is a nuclear, not cytoplasmic, defect. Nature 308: 550-551.

McLaren A. 1979. Maternal effects in development: The fourth symposium of the British Society for Developmental Biology (ed. Newth DR, Balls M). Cambridge University Press, Cambridge.

Moore T, Haig D. 1991. Genomic imprinting in mammalian development: A parental tug-of-war. Trends Genet 7: 45-49.
Moore T, Constancia M, Zubair M, Bailleul B, Feil R, Sasaki H, Reik W. 1997. Multiple imprinted sense and antisense transcripts, differential methylation and tandem repeats in a putative imprinting control region upstream of mouse Igf2. Proc Natl Acad Sci 94: 12509-12514.

Morgan DH, Santos F, Green K, Dean W, Reik W. 2005. Epigenetic reprogramming in mammals. Hum Mol Genet 14: R47-R48.

Nagano T, Mitchell JA, Sanz LA, Pauler FM, Ferguson-Smith AC, Feil R, Fraser P. 2008. The Air noncoding RNA epigenetically silences transcription by targeting G9a to chromatin. Science 322: 1717-1720.

Nakamura T, Liu YY, Nakashima H, Umehara H, Inoue K, Matoa S, Tachibana M, Ogura A, Shinkai Y, Nakana T. 2012. PGC7 binds histone $\mathrm{H} 3 \mathrm{~K} 9 \mathrm{me} 2$ to protect against conversion of $5 \mathrm{mC}$ to $5 \mathrm{hmC}$ in early embryos. Nature 486: 415-419.

Nativio R, Wendt KS, Ito Y, Huddleston JE, Uribe-Lewis S, Woodfine K, Krueger C, Reik W, Peters JM, Murrell A. 2009. Cohesin is required for higher-order chromatin conformation at the imprinted IGF2-H19 locus. PLOS Genet 5: e1000739.

Neumann B, Kubicka P, Barlow DP. 1995. Characteristics of imprinted genes. Nat Genet 9: 12-13.

Ooi SK, Qiu C, Bernstein E, Li K, Jia D, Yang Z, Erdjument-Bromage H, Tempst P, Lin SP, Allis CD, et al. 2007. DNMT3L connects unmethylated lysine 4 of histone $\mathrm{H} 3$ to de novo methylation of DNA. Nature 448: $714-717$.

Pandey RR, Mondal T, Mohammad F, Enroth S, Redrup L, Komorowski J, Nagano T, Mancini-Dinardo D, Kanduri C. 2008. Kcnqlot1 antisense noncoding RNA mediates lineage-specific transcriptional silencing through chromatin-level regulation. Mol Cell 32: 232-246.

Pauler FJ, Barlow DP, Hudson QJ. 2012. Mechanisms of long range silencing by imprinted macro non-coding RNAs. Curr Opin Genet Dev 22: $1-7$.

Prickett AR, Oakey RJ. 2012. A survey of tissue-specific imprinting in mammals. Mol Genet Genomics 287: 621-630.

Quenneville S, Verde G, Corsinotti A, Kapopoulou A, Jakobsson J, Offner S, Baglivo I, Pedone PV, Grimaldi G, Riccio A, et al. 2011. In embryonic stem cells, ZFP57/KAP1 recognize a methylated hexanucleotide to affect chromatin and DNA methylation of imprinting control regions. Mol Cell 44: 361-377.

Rabinowicz PD, Palmer LE, May BP, Hemann MT, Lowe SW, McCombie WR, Martienssen RA. 2003. Genes and transposons are differentially methylated in plants, but not in mammals. Genome Res 13: 26582664.

Rando TA, Chang HY. 2012. Aging, rejuvenation and epigenetic reprogramming: Resetting the aging clock. Cell 148: 46-57.

Redrup L, Branco MR, Perdeaux ER, Krueger C, Lewis A, Santos F, Nagano T, Cobb BS, Fraser P, Reik W. 2009. The long noncoding RNA Kcnq1ot1 organises a lineage-specific nuclear domain for epigenetic gene silencing. Development 136: 525-530.

Reik W. 1989. Genomic imprinting and genetic disorders in man. Trends Genet 5: 331-336.

Reik W, Howlett SK, Surani MA. 1990. Imprinting by DNA methylation: From transgenes to endogenous gene sequences. Dev Suppl 1990: 99106.

Renfree MB, Hore TA, Shaw G, Graves JA, Pask AJ. 2009. Evolution of genomic imprinting: Insights from marsupials and monotremes. Annu Rev Genomics Hum Genet 10: 214-262.

* Rinn JL. 2014. Linking RNA to chromatin. Cold Spring Harb Perspect Biol doi: $10.1101 /$ cshperspect.a018614.

Robson JE, Eaton SA, Underhill P, Williams D, Peter J. 2012. MicroRNAs 296 and 298 are imprinted and part of the GNAS/Gnas cluster and miR-296 targets IKBKE and Tmed 9. RNA 18: 135-144.

Sasaki H, Jones PA, Chaillet JR, Ferguson-Smith AC, Barton SC, Reik W, Surani MA. 1992. Parental imprinting: Potentially active chromatin of the repressed maternal allele of the mouse insulin-like growth factor II (Igf2) gene. Genes Dev 6: 1843-1856.

Schmidt JV, Levorse JM, Tilghman SM. 1999. Enhancer competition between $\mathrm{H} 19$ and Igf2 does not mediate their imprinting. Proc Natl Acad Sci 96: 9733-9738. 
Searle AG, Beechey CV. 1978. Complementation studies with mouse translocations. Cytogenet Cell Genet 20: 282-303.

Seidl CI, Stricker SH, Barlow DP. 2006. The imprinted Air ncRNA is an atypical RNAPII transcript that evades splicing and escapes nuclear export. EMBO J 25: 3565-3567.

Seitz H, Royo H, Lin SP, Youngson N, Ferguson-Smith AC, Cavaille J. 2004. Imprinted small RNA genes. Biol Chem 385: 905-911.

Shemer R, Birger Y, Riggs AD, Razin A. 1997. Structure of the imprinted mouse Snrpn gene and establishment of its parental-specific methylation pattern. Proc Natl Acad Sci 94: 10267-10272.

Shin JY, Fitzpatrick GV, Higgins MJ. 2008. Two distinct mechanisms of silencing by the KvDMR1 imprinting control region. EMBO $J$ 27: $168-178$.

Shiura H, Nakamura K, Hikichi T, Hino T, Oda K, Suzuki-Migishima R, Kohda T, Kaneko-Ishino T, Ishino F. 2009. Paternal deletion of Meg1/ Grb10 DMR causes maternalization of the Meg1/Grb10 cluster in mouse proximal Chromosome 11 leading to severe pre- and postnatal growth retardation. Hum Mol Genet 18: 1424-1438.

Sleutels F, Tjon G, Ludwig T, Barlow DP. 2003. Imprinted silencing of Slc22a2 and Slc22a3 does not need transcriptional overlap between Igf2r and Air. EMBO J 22: 3696-3704.

Sleutels F, Zwart R, Barlow DP. 2002. The non-coding Air RNA is required for silencing autosomal imprinted genes. Nature 415: 810-813.

Stoger R, Kubicka P, Liu CG, Kafri T, Razin A, Cedar H, Barlow DP. 1993. Maternal-specific methylation of the imprinted mouse Igf2r locus identifies the expressed locus as carrying the imprinting signal. Cell 73: 61-71.

Surani MA, Barton SC, Norris ML. 1984. Development of reconstituted mouse eggs suggests imprinting of the genome during gametogenesis. Nature 308: 548-550.

Takada S, Paulsen M, Tevendale M, Tsai CE, Kelsey G, Cattanach BM, Ferguson-Smith AC. 2002. Epigenetic analysis of the Dlk1-Gtl2 imprinted domain on mouse chromosome 12: Implications for imprinting control from comparison with Igf2-H19. Hum Mol Genet 11: $77-86$.

Tan L, Shi YG. 2012. Tet family proteins and 5-hydroxymethylcytosine in development and disease. Development 139: 1895-1902.

Terranova R, Yokobayashi S, Stadler MB, Otte AP, van Lohuizen M, Orkin SH, Peters AH. 2008. Polycomb group proteins Ezh2 and Rnf2 direct genomic contraction and imprinted repression in early mouse embryos. Dev Cell 15: 668-679.

Thorvaldsen JL, Duran KL, Bartolomei MS. 1998. Deletion of the H19 differentially methylated domain results in loss of imprinted expression of H19 and Igf2. Genes Dev 12: 3693-3702.
Tierling S, Dalbert S, Schoppenhorst S, Tsai CE, Oliger S, FergusonSmith AC, Paulsen M, Walter J. 2005. High-resolution map and imprinting analysis of the Gtl2-Dnchc1 domain on mouse chromosome 12. Genomics 87: 225-235.

Varmuza S, Mann M. 1994. Genomic imprinting-defusing the ovarian time bomb. Trends Genet 10: 118-123.

Wan LB, Bartolomei MS. 2008. Regulation of imprinting in clusters: Noncoding RNAs versus insulators. Adv Genet 61: 207-223.

Wilkins JF, Haig D. 2003. What good is genomic imprinting: The function of parent-specific gene expression. Nat Rev Genet 4: 359-368.

Williamson CM, Turner MD, Ball ST, Nottingham WT, Glenister P, Fray M, Tymowska-Lalanne Z, Plagge A, Powles-Glover N, Kelsey G, et al. 2006. Identification of an imprinting control region affecting the expression of all transcripts in the Gnas cluster. Nat Genet 38: $350-$ 355.

Williamson CM, Ball ST, Dawson C, Mehta S, Beechey CV, Fray M, Teboul L, Dear TN, Kelsey G, Peters J. 2011. Uncoupling antisense-mediated silencing and DNA methylation in the imprinted Gnas cluster. PLoS Genet 7: e1001247.

Wood AJ, Schulz R, Woodfine K, Koltowska K, Beechey CV, Peters J, Bourc'his D, Oakey RJ. 2008. Regulation of alternative polyadenylation by genomic imprinting. Genes Dev 22: 1141-1146.

Wutz A, Smrzka OW, Schweifer N, Schellander K, Wagner EF, Barlow DP. 1997. Imprinted expression of the Igf2r gene depends on an intronic CpG island. Nature 389: 745-749.

Xie W, Barr CL, Kim A, Yue F, Lee AY, Eubanks J, Dempster EL, Ren B. 2012. Base-resolution analyses of sequence and parent-of-origin dependent DNa methylation in the mouse genome. Cell 148: 816-831.

Yatsuki H, Joh K, Higashimoto K, Soejima H, Arai Y, Wang Y, Hatada I, Obata Y, Morisaki H, Zhang Z, et al. 2002. Domain regulation of imprinting cluster in Kip2/Lit1 subdomain on mouse chromosome 7F4/F5: Large-scale DNA methylation analysis reveals that DMR-Lit1 is a putative imprinting control region. Genome Res 12: $1860-1870$.

Zwart R, Sleutels F, Wutz A, Schinkel AH, Barlow DP. 2001. Bidirectional action of the Igf2r imprint control element on upstream and downstream imprinted genes. Genes Dev 15: 2361-2366.

\section{WWW RESOURCES}

http://www.mousebook.org/catalog.php?catalog=imprinting MouseBook, Medical Research Council. 


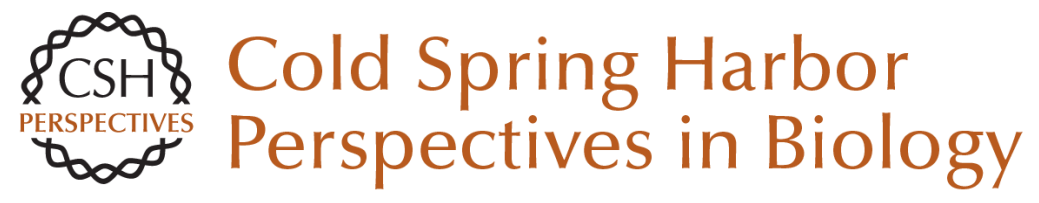

\section{Genomic Imprinting in Mammals}

Denise P. Barlow and Marisa S. Bartolomei

Cold Spring Harb Perspect Biol 2014; doi: 10.1101/cshperspect.a018382

\section{Subject Collection Epigenetics}

Metabolic Signaling to Chromatin Shelley L. Berger and Paolo Sassone-Corsi

Histone and DNA Modifications as Regulators of Neuronal Development and Function Stavros Lomvardas and Tom Maniatis

Histone Modifications and Cancer James E. Audia and Robert M. Campbell

Epigenetics and Human Disease Huda Y. Zoghbi and Arthur L. Beaudet

Induced Pluripotency and Epigenetic Reprogramming Konrad Hochedlinger and Rudolf Jaenisch

Long-Range Chromatin Interactions Job Dekker and Tom Misteli

RNAi and Heterochromatin Assembly Robert Martienssen and Danesh Moazed

Dosage Compensation in Drosophila John C. Lucchesi and Mitzi I. Kuroda
Epigenetic Determinants of Cancer Stephen B. Baylin and Peter A. Jones

Maintenance of Epigenetic Information Geneviève Almouzni and Howard Cedar

A Structural Perspective on Readout of Epigenetic Histone and DNA Methylation Marks Dinshaw J. Patel

The Necessity of Chromatin: A View in

Perspective Vincenzo Pirrotta

Germline and Pluripotent Stem Cells Wolf Reik and M. Azim Surani

Comprehensive Catalog of Currently Documented Histone Modifications Yingming Zhao and Benjamin A. Garcia

Epigenetic Regulation of Chromatin States in Schizosaccharomyces pombe Robin C. Allshire and Karl Ekwall

Histone Variants and Epigenetics Steven Henikoff and M. Mitchell Smith

For additional articles in this collection, see http://cshperspectives.cshlp.org/cgi/collection/

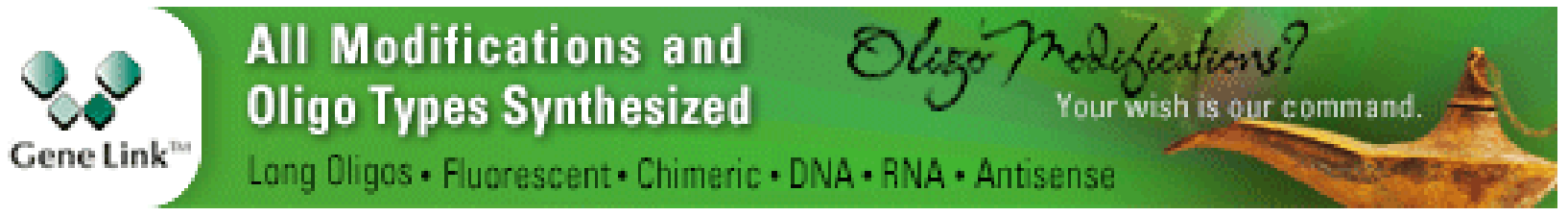

Copyright @ 2014 Cold Spring Harbor Laboratory Press; all rights reserved 
For additional articles in this collection, see http://cshperspectives.cshlp.org/cgi/collection/

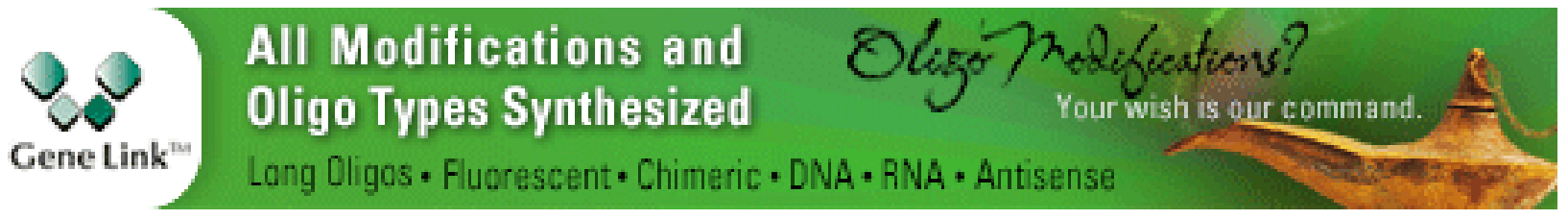

Copyright @ 2014 Cold Spring Harbor Laboratory Press; all rights reserved 